\title{
LA ACTIVIDAD LABORAL DE LAS FAMILIAS AFRICANAS Y LATINOAMERICANAS REAGRUPADAS EN LA ESPAÑA MEDITERRÁNEA ${ }^{1}$
}

\author{
Vicente Gozálvez Pérez et al. ${ }^{2}$ \\ Departamento de Geografía Humana \\ Universidad de Alicante
}

\section{RESUMEN}

La investigación se basa en los resultados de una encuesta realizada en 2009-2010, por el equipo investigador, a 348 inmigrados reagrupantes africanos y a 457 latinoamericanos que residen en las provincias litorales entre Girona y Almería. La información que se ofrece está referida a los aspectos laborales de estos dos colectivos continentales, tanto a escala del conjunto territorial indicado como para tres subáreas incluidas en él: Cataluña litoral, Comunidad Valenciana y Murcia-Almería; según los temas, se trata por separado a los reagrupantes y a los subgrupos familiares que conviven en España (reagrupantes, cónyuges, hijos). El estudio se centra en las estructuras de empleo por sectores económicos. También se estudian las redes migratorias, tan decisivas en la orientación de estos flujos hacia España, la regulación laboral de estos trabajadores, la repercusión de la crisis actual en los empleos de las familias reagrupadas (paro, número de ocupados por familia e ingresos), la satisfacción laboral de los miembros de las familias (horas de trabajo, problemas laborales y salariales) y la estabilidad laboral (antigüedad en el empleo, cursos de formación

1 Investigación realizada dentro del proyecto «La reagrupación familiar de los inmigrantes africanos y latinoamericanos en la España mediterránea», Ref. CSO2008-01796, financiado por el Ministerio de Ciencia e Innovación. La encuesta a los reagrupantes que proporciona los datos básicos para este texto, se ha realizado dentro del Proyecto citado.

2 J.D. Sempere Souvannavong, G. Martín-Serrano Rodríguez, A. Espinosa Seguí, J.A. Larrosa Rocamora, E. Cutillas Orgilés, X. Amat Montesinos, C. Cortés Samper, R. Díez Ros, J.R. Valero Escandell, S. Palazón Ferrando. Gabino Martín-Serrano realizó la graficación. 
profesional, trabajo actual y expectativas del inmigrante). El recorrido por los temas laborales indicados, vinculados a los distintos grupos continentales y familiares y a las diferentes escalas territoriales, concluyen en mostrar situaciones económicas y sociales muy diferentes entre africanos y latinoamericanos, y entre los que residen en Cataluña litoral y en Murcia-Almería, en lo que intervienen, entre otras causas, los distintos «capitales» personales aportados por los dos colectivos continentales para acceder al empleo (formación, idioma, ...) y las diferentes estructuras económicas de los territorios estudiados. Los africanos y los que residen en las provincias meridionales son los que presentan peores situaciones socioeconómicas.

Palabras clave: Reagrupación familiar, africanos, latinoamericanos, estructuras de empleo, situaciones laborales, condicionantes laborales, España mediterránea

\begin{abstract}
This research is based on the results of a survey administered by the research team in 2009-2010 with 348 African and 457 Latin American family reunification immigrants living in the coastal provinces of Spain between Girona and Almería. The results provide information on the employment situation of the two groups from separate continents both for the study area as a whole and for three smaller areas: coastal Catalonia, the Region of Valencia and MurciaAlmería. Due to certain issues, sponsor immigrants and reunified families (i.e. sponsor, spouse and children living together in Spain) are treated separately. The study focuses on employment structures by economic sector, as well as migratory networks, which are crucial in the direction of these flows towards Spain, employment regulations for these workers, how the current crisis is affecting reunified families (unemployment, number of people per family in work, and income), job satisfaction of family members (working hours, and employment and wage problems) and job stability (time in employment, professional training courses, current job and immigrant's expectations). Following analysis of these employment issues and their links to the two groups of immigrants and their families, as well as to the different regional areas, very different economic and social situations are shown to exist between Africans and Latin Americans. Differences are also shown between those living on the coast of Catalonia and in Murcia-Almería, as a result, among other causes, of the various personal «capital» brought by the two groups of immigrants in order to gain access to the job market (training, language, etc.) and the different economic structure of the areas studied. The worst economic situations were reported for Africans and for immigrants living in the southern provinces of the area studied.
\end{abstract}

Keywords: Family reunification, Africans, Latin Americans, employment structures, employment situations, working conditions, Mediterranean Spain 


\section{INTRODUCCIÓN}

Los extranjeros residentes en España son objeto de atención destacada para la sociedad, para los medios de comunicación y para las autoridades político-administrativas del país desde 1985, cuando se promulgó la Ley Orgánica 7/1985, de 1 de julio, sobre derechos y libertades de los extranjeros en España. En ese año, los extranjeros censados por el Ministerio del Interior eran 242.000, de los que dos tercios tenían nacionalidades de países desarrollados, fundamentalmente de Europa Occidental, aunque la atención y preocupación social, política y de los medios de comunicación se centraba en los extranjeros que llegaban en busca de trabajo desde países en desarrollo, especialmente desde África, cuyo acceso y/o permanencia en España en su mayoría escapaba a las estadísticas oficiales (Gozálvez, 1990; Gozálvez, 2012a).

En 1991 se inicia la regularización de las estadísticas oficiales sobre los extranjeros, pero sólo en 1998, con el inicio de la publicación del Padrón continuo de habitantes por parte del Instituto Nacional de Estadística, se dispondrá de una estadística oficial para evaluar -de forma limitada- el número de extranjeros en situación irregular, asimilable a la diferencia positiva de los extranjeros empadronados sobre las cifras de los regularizados ofrecidas por el Ministerio del Interior. Entre 1992 y 1998 los incrementos anuales de extranjeros ofrecidos por el Ministerio del Interior oscilan entre 30.000 y 40.000, con stock total de 637.000 en 1998. En el año 2000, según el Padrón de Habitantes, los extranjeros suman 924.000 y superan por primera vez el 2\% de la población de España, de los que Europa Occidental aún aportaba el contingente continental más numeroso, el $43 \%$ del total, seguido por los africanos (25\%) y los latinoamericanos (20\%).

Con fecha de 1 de enero de 2011, los extranjeros residentes en España, según el Padrón de Habitantes, son 5.751.487, que representan el 12,2\% de la población total del país (47.190.493 habitantes). Del total de extranjeros, tienen nacionalidades africanas 1.084.793 y nacionalidades de América Latina 1.659.026. Por otra parte, de los censos actuales, el $87 \%$ de los latinoamericanos y el 79\% de los africanos son incrementos netos respecto a los empadronados el 1 de enero de 2000.

Durante los años de inmigración masiva -de 1998 a 2007-, los incrementos anuales de inmigración en España fueron del 18\% en los africanos y del 29\% en los latinoamericanos, con una media nacional de incremento de stock de 452.000 extranjeros anuales. El inicio de la crisis económica-laboral en 2008 ha paralizado el crecimiento de la década anterior, cuya continuidad es difícilmente asumible tanto económica como socialmente. En 2009, el saldo neto nacional de la inmigración extranjera se redujo a 99.000 y a sólo 3.753 durante 2010; el retorno a un nuevo ciclo inmigratorio con las características de los años 1998-2007 parece desvanecido, aunque sin duda alguna, la inmigración por reagrupación familiar puede alimentar saneados saldos inmigratorios durante los próximos años, tal como ya 
ocurrió a partir de 1973 en países europeos de nuestro entorno (Bel Hadj Zekri, 1996; Fadloullah, 1996; Içduygu, 1996). Los elevados contingentes de inmigrantes jóvenes ya asentados en España, su cultura diferente a la de los autóctonos, su generalizada y firme voluntad de permanencia en España, tanto de los mismos inmigrantes adultos como sobre todo para sus hijos -especialmente entre los africanos-, parecen motivos acordes a una evolución positiva de inmigrantes por razones de reagrupación familiar, fundamentalmente de cónyuges e hijos (Gozálvez et al., 2012b). Este nuevo ciclo inmigratorio, también puede ser «potenciado» por factores internos de España, como es la insuficiente fecundidad del país, su envejecimiento progresivo o el cambio en las estructuras laborales, entre otras causas (Gozálvez, 2010; Pumares, 2006). De hecho, la fecundidad de las mujeres extranjeras residentes en España no solventan la renovación de generación (2,1 hijos por mujer), pues, en 2008, el conjunto de las extranjeras tenían 1,79 hijos por mujer, frente a 1,36 de las españolas (Gozálvez, 2010).

Figura 1. Localización de la zona estudiada. Las cifras indican el número total de africanos y latinoamericanos, ambos sexos, que recoge el Padrón de habitantes de

2009 para cada una de las tres áreas (Instituto Nacional de Estadística). Los africanos de las tres áreas suman el 51\% de su total empadronado en España, y el 38\% los latinoamericanos.

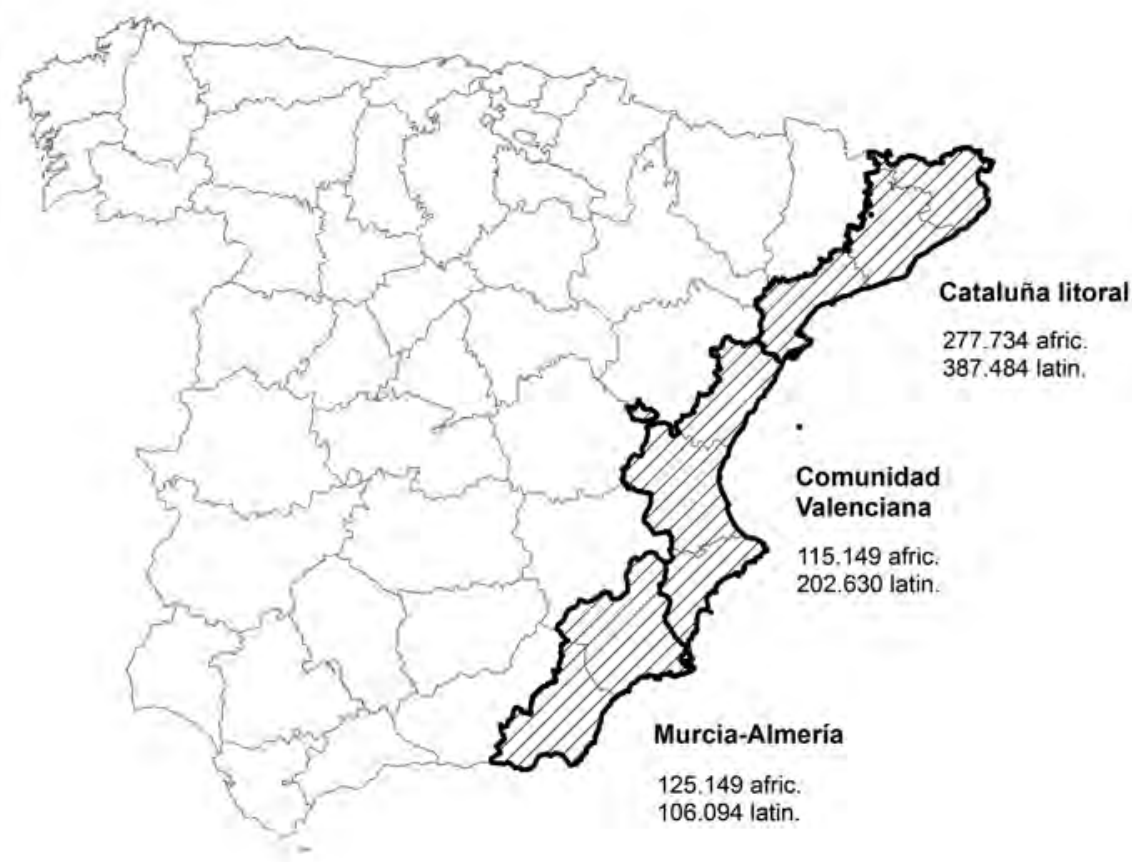


La fuerte inflexión inmigratoria de España iniciada en 2009 está ligada fundamentalmente a la autorregulación migratoria impuesta, tanto en origen como en España, por la crisis económico-laboral que padece España desde 2008, pero también a las políticas de lucha contra la inmigración irregular, a los recortes de los contratos laborales para inmigrantes en origen o a los incentivos del Gobierno de España para el retorno voluntario de inmigrantes a sus países de origen, entre otras causas (Cusi, 2011). La autorregulación inmigratoria en origen, así como los retornos de los inmigrados ya residentes en España, que ha impuesto la crisis económico-laboral, tienen su mayor efectividad en los flujos latinoamericanos, pues éste es el único contingente continental que ha tenido saldos migratorios negativos durante 2009 (-55.000) y 2010 (-101.000), generalizados en todos los países con mayor presencia inmigratoria en España.

El balance de los elevados stocks de inmigrados africanos y latinoamericanos residentes en España, de sus características sociodemográficas, de sus proyectos migratorios, así como de las posibilidades de futuro en España o en el país de origen, entre otros aspectos, sitúan a estos dos grandes colectivos continentales como objeto de especial atención para su estudio y para las políticas a desarrollar en España, tendentes a conseguir un nivel satisfactorio en su integración económica y social, tanto en la actualidad como para las próximas décadas. La historia recorrida por países europeos de nuestro entorno, más precoces que España en la inmigración extranjera y en la reagrupación familiar de los inmigrados, ilustran bien la necesidad de prever posibles futuros problemas que pueden surgir por integraciones económicas y sociales insuficientes, sobre todo para las generaciones producidas por la inmigración (Dumont, 2008), especialmente de la que tiene origen en los países surmediterráneos. En efecto, estos últimos inmigrantes suelen estar «mal protegidos» por un capital personal muy insuficiente para su integración económica y social -bajo nivel de instrucción, desconocimiento de la lengua local, diferencias culturales...-, lo que les produce, a ellos y a sus hijos, marginación visible tanto en lo económico como en lo social respecto a la sociedad en la que se insertan, sobre todo cuando estos inmigrantes «se segregan» a favor de barrios urbanos «especializados» en residentes con estos orígenes; estas segregaciones a veces se producen de forma voluntaria (p.e. por lazos familiares o de amistad), pero con frecuencia también forzosamente a causa de los precios del mercado de la vivienda.

El estudio de la inmigración extranjera que llega buscando mejorar su situación económica y social, interrelacionada con sus países de procedencia, con su estructura sociodemográfica, con su antigüedad en los territorios de acogida, o con su inicial inserción laboral y social en las áreas de asentamiento en España, entre otros aspectos, es esencial para valorar evoluciones y repercusiones futuras de estos colectivos en los territorios de inmigración. Aunque las migraciones 
internacionales siempre han tenido un efecto final positivo en el progreso de las sociedades, las migraciones masivas, sobre todo cuando se producen con irregularidades administrativo-legales y con mercados laborales en dificultades, en general a corto plazo tienen efectos perturbadores en las sociedades de acogida, que afectan negativamente a la integración económica y social de los migrantes ante el rechazodesconfianza que surge tanto de las sociedades de acogida como de los mismos inmigrantes, hechos patentes en España. Ante estos conflictos-preocupaciones, es preciso buscar activamente soluciones por parte de ambas sociedades involucradas en estos flujos migratorios (Tribalat, 2012), línea en la que se inscribe esta investigación sobre las características laborales de las familias reagrupadas.

Los efectos de la inmigración extranjera sobre el territorio se apoyan sobre dos criterios geográficos principales: el origen geográfico de los inmigrantes y las características económicas del territorio sobre el que se instalan (Dumont, 2008). El efecto de la nacionalidad de los inmigrantes sobre sus posibilidades de integración económica en los territorios de inmigración, medido a través de su situación y estructura laborales, se asocia a factores que el inmigrante aporta de origen como capital propio, sobre todo su nivel de instrucción, su lengua materna y su cultura. La estructura económica del territorio local de residencia de los inmigrantes, delimita, por su parte, las posibilidades de desarrollo del capital humano que aporte el inmigrante (Pumares y Jolivet, 2011). En este sentido, el tiempo de residencia del inmigrante en el país de acogida es, a su vez, «parte» de los territorios locales de acogida, pues el tiempo de residencia tiene efectos diferentes en la evolución socioeconómica tanto del inmigrante como de los territorios.

Estos grandes condicionantes para las posibilidades de integración económica y social del inmigrante extranjero en la España mediterránea -país de origen del inmigrante, área de residencia del inmigrado, tiempo de residencia en España-, se constatan de forma paradigmática en los dos colectivos continentales elegidos para esta investigación, africanos y latinoamericanos. La división regional de la España mediterránea -Cataluña litoral, Comunidad Valenciana y MurciaAlmería- ilustra bien las distintas posibilidades que ofrecen estos territorios a los dos colectivos estudiados. Asimismo, los efectos de la antigüedad de residencia en el país, quedan contrastados, como veremos, en los cambios que se producen en la situación y en la estructura laboral de los reagrupantes de cada uno de los dos colectivos continentales. En nuestro caso, el efecto de la antigüedad en el territorio de acogida lo vinculamos a la situación y estructura laborales del reagrupante en su primer trabajo en España, en el trabajo que tenía cuando realizó su reagrupación familiar y en el que tiene en la actualidad o momento en que se realiza la encuesta a los reagrupantes (2009-2010); esta encuesta es la fuente básica en la que se basa esta investigación. 


\section{ASPECTOS METODOLÓGICOS}

La encuesta en la que se basa esta investigación (Encuesta sobre reagrupación familiar realizada en 2009-2010 a inmigrados reagrupantes africanos y latinoamericanos que residen en la España mediterránea) forma parte del Proyecto CS02008-01796, citado en la nota 1. Este proyecto continúa otros proyectos anteriores, también realizados por el mismo equipo de investigación y sobre la misma área geográfica, aunque los colectivos estudiados, así como las respectivas encuestas, tuvieron sus propias especificidades: inmigrados marroquíes y senegaleses (Proyecto SEC92-0354), inmigrados africanos (Proyecto SEC98-0628) y mujeres africanas y latinoamericanas (Proyecto BS02002-00229). Esta serie de proyectos de investigación anteriores permiten confirmar, en su caso, muchas conclusiones obtenidas de la encuesta que ahora se utiliza.

La encuesta fue realizada por muestreo aleatorio estratificado en 2009-10 a 805 inmigrados reagrupantes, africanos y latinoamericanos de ambos sexos, mayores de 25 años de edad, que residen en las ocho provincias litorales entre Girona y Almería, y que conviven con sus familiares (cónyuges, hijos, progenitores y otros familiares). Una parte de estos familiares del reagrupante llegaron a España de acuerdo con las leyes de reagrupación familiar, mientras que otros, según las declaraciones de los reagrupantes, son ajenos a este procedimiento, sobre todo porque han nacido en España, accedieron al país de forma independiente o simplemente, llegaron al margen de las leyes de inmigración/reagrupación, pero que han terminado como parte de estos hogares familiares.

La información de esta encuesta se ofrece a dos escalas territoriales principales: por una parte, para el conjunto de las ocho provincias, distinguiendo africanos y latinoamericanos, y por otra, para tres subáreas territoriales, como son Cataluña litoral, Comunidad Valenciana y Murcia-Almería, siempre con referencia a los dos conjuntos continentales, africanos y latinoamericanos, en cada subárea. El cuestionario diseñado para este proyecto es de preguntas cerradas y fue cumplimentado mediante entrevista personal a los reagrupantes. La información de esta encuesta se agrupa en los apartados siguientes: 1. Sociodemografía; 2 . Familia y escuela; 3 . Tiempo libre; 4. Entrada en España del reagrupante y su primer trabajo; 5. Condiciones actuales de trabajo en España de la familia del reagrupante; 6. Problemas laborales y de salario; 7. Alojamiento y barrio; 8 . Otros (previsión del reagrupante sobre tiempo de permanencia en España de él y de sus hijos, inmigración a España de otros familiares, fecundidad de las hijas del reagrupante, comunicación familiar con el país de origen, cuantía de los ingresos mensuales familiares, gastos principales, etc.

El muestreo aleatorio estratificado para aplicar la encuesta citada, se ha realizado de acuerdo con las nacionalidades de los inmigrados de cada continente, según el Padrón municipal de habitantes de 2009. Para el conjunto de las ocho 
provincias estudiadas -las litorales entre Girona y Almería-, se ha seleccionada una muestra de 457 encuestas a reagrupantes latinoamericanos que suponen un margen de error de $\pm 5 \%$ en un nivel de confianza del $95 \%$ y $\mathrm{P}=0,5$, y de $\pm 7 \%$ para los africanos -muestra de 348 encuestas-. Cuando se desciende a cada uno de los tres ámbitos territoriales utilizados en la investigación -Cataluña litoral, Comunidad Valenciana y Murcia-Almería-, el margen de error sube a $\pm 10 \%$-para el mismo intervalo de confianza- para cada uno de los dos grupos de nacionalidades, excepto para los latinoamericanos en Cataluña, con $\pm 7 \%$. En concreto, para Cataluña litoral se realizaron y validaron 127 encuestas a reagrupantes africanos y 216 a latinoamericanos; para la Comunidad Valenciana 122 encuestas a africanos y 136 a latinoamericanos, y para Murcia-Almería, 99 encuestas a africanos y 105 a latinoamericanos. El tamaño de la población representada por la muestra, africanos y latinoamericanos de ambos sexos mayores de 25 años de edad, según el Padrón de habitantes de 2009 ascendía en la zona estudiada a 331.000 africanos y 487.000 latinoamericanos, de los que residían en Cataluña litoral 180.000 africanos y 271.000 latinoamericanos, en la Comunidad Valenciana 69.000 y 142.000, y en Murcia-Almería 81.000 y 74.000; estas cifras de mayores de 25 años han sido calculadas a partir de la proporción del total nacional por edades de africanos y latinoamericanos.

Los territorios estudiados se justifican porque el conjunto del área litoral es sin duda la zona de España más caracterizada por la inmigración extranjera de todas las procedencias, incluidos los dos colectivos continentales indicados. Cataluña es, en términos generales, la región con la inmigración más antigua, sobre todo la africana (Gozálvez, 1990); aquí la inmigración está más vinculada a la urbanización y a una mayor variedad y cantidad de empleos ofertados a los inmigrantes. Por el contrario, Murcia-Almería, dentro de las especifidades de cada provincia, es el área donde la inmigración es más reciente dentro de la España mediterránea, la más vinculada con la agricultura intensiva y minifundista (Gozálvez y López Trigal, 1999; Cohen y Berriane (dir.), 2011), y también es la zona que ofrece menor variedad de empleo a los inmigrados africanos y latinoamericanos andinos, que son los que predominan en estas dos provincias.

Estas características de los territorios y de sus inmigrantes extranjeros, tienen fiel reflejo, como se verá, entre los reagrupantes africanos y latinoamericanos encuestados, que se resume en que Cataluña concentra el capital inmigratorio mejor preparado, mientras en Murcia-Almería ocurre lo contrario. La elección de africanos y latinoamericanos para estudiar la reagrupación familiar, radica tanto en las dinámicas habidas y previstas en ambos contingentes, en sus características, así como en su protagonismo en concentrar los reagrupados familiares que llegan al país (Gozálvez et al., 2012b). 


\section{IMPORTANCIA DE LAS REDES MIGRATORIAS PARA LA ELECCIÓN DE ESPAÑA COMO PAÍS DE INMIGRACIÓN}

Los inmigrados africanos y latinoamericanos que han realizado reagrupación familiar en España, sin duda forman una categoría de especial valoración positiva entre los que llegaron por motivos de trabajo, casi siempre sin el apoyo de un contrato laboral previo a su expatriación, que garantizara, al menos inicialmente, el éxito del siempre difícil proceso emigratorio. En efecto, los reagrupantes familiares son inmigrados que en su momento lograron estabilizar su presencia en España, pues la reagrupación familiar les exigió previamente tener contrato estable de trabajo, ingresos suficientes para atender a su familia en España, así como disponer de una vivienda adecuada. Esta situación de estabilidad laboral, residencial y familiar ha inducido cambios positivos en la estructura del empleo del reagrupante, lo que se estudiará con detalle.

Las declaraciones económico-laborales de los reagrupantes encuestados en la España mediterránea, sin duda alcanzan fiabilidad suficiente para valorar, en parte, sus procesos migratorios. Es conocido que en la difícil decisión final de emigrar por motivos laborales, como es el caso que nos ocupa, intervienen variados agentes y motivos, que cada migrante jerarquiza. Por ello, la idea y las motivaciones que llevaron al migrante a su expatriación deben ser valoradas no como únicas, sino como las más determinantes entre las varias que el migrante valora o que la encuesta realizada les propone.

\subsection{Los «responsables» de la idea de emigrar a España}

Entre los reagrupantes encuestados, la idea de emigrar a España es valorada en la encuesta hasta con dos respuestas (por lo que se contabilizan 410 respuestas entre los africanos y 552 entre los latinoamericanos), entre las que sobresalen dos para ambos colectivos, y con el mismo orden de jerarquía: las redes migratorias de familiares y amigos ya inmigrados en España, y el propio « afán de superación », aunque la doble respuesta puede incluir al mismo migrante en ambos casos. Para los reagrupantes africanos, las redes migratorias constituidas por sus familiares y amigos ya inmigrados en España suman el 44\% de las respuestas, de las que la cuarta parte son atribuidas a los familiares. Por su parte, la iniciativa del propio migrante " por afán de superación » alcanza el 40\% de todas las respuestas. Los familiares y amigos del reagrupante que residían en el país de origen influyen poco en su decisión de emigrar a España, pues sólo suman el 10\% de las respuestas, repartidas casi por mitad entre familiares y amigos.

Para los reagrupantes latinoamericanos, la idea de emigrar a España también la identifican mayoritariamente con sus familiares (31\%) y amigos (19\%), es 
decir, la red migratoria sumaría la mitad de todas las respuestas sobre los responsables de su orientación emigratoria hacia España. Los familiares y amigos residentes en el país de origen del migrante latinoamericano tienen, igual que sucede entre los africanos, importancia secundaria (16\% de las respuestas) en la orientación de destino para el nuevo emigrante.

Aunque con frecuencia se ha repetido que la televisión, prensa y opinión pública eran agentes con notable influencia en la orientación de los flujos emigratorios hacia España, esta afirmación carece de valor según las declaraciones de los reagrupantes, pues sólo el $2 \%$ de los africanos y el 1\% de los latinoamericanos admiten como decisiva esta causa de orientación migratoria.

La distribución territorial de las proporciones sobre la responsabilidad de la orientación emigratoria hacia España, ofrece valores similares a los ya señalados para el conjunto de la España mediterránea estudiada, excepto entre los reagrupantes que residen en Murcia-Almería: en este caso, por una parte, aumenta mucho $(40 \%)$ la responsabilidad atribuida a los familiares latinoamericanos ya inmigrados en España, lo que se explicaría por el lógico desconocimiento de esta área inmigratoria entre los andinos, que son la mayoría de los que aquí residen. Por otra parte, cuando la idea de la emigración hacia España es atribuida al afán de superación del propio emigrante, las proporciones de los residentes en Murcia-Almería disminuyen, sobre todo entre los latinoamericanos (24\%), respecto a la media del conjunto territorial estudiado (31\%), lo que sin duda se vincula a sus altas tasas de empleo agrario en estas dos provincias, sector de empleo que generalmente no es deseado para el proyecto emigratorio del reagrupante (insuficiencia de sus salarios, dureza del trabajo, sobre todo para los de origen urbano,...).

Las altas tasas que los reagrupantes atribuyen a sus familiares ya inmigrados en España como responsables de su decisión de emigrar a este mismo país, es acorde a la mayor confianza que éstos le inspiran ante las incertidumbres que el emigrante tiene cuando va a emprender, casi siempre por primera vez en su vida, una emigración internacional, bien a un país lejano (latinoamericanos), bien a un país con costumbres y lengua diferentes a las de su sociedad de origen (africanos). La información y sin duda también los ofrecimientos que los familiares ya emigrados transmiten a los nuevos candidatos a emigrar, fundamentalmente sobre las posibilidades de empleo en el país y las necesarias y relativamente complicadas tramitaciones burocráticas que este exige, las posibilidades de alojamiento inicial ofertadas, etc., todo ello dentro de la solidaridad familiar, son sin duda determinantes para el nuevo emigrante. La importancia de estos contactos de acogida para el nuevo inmigrante, son resaltados en todas las encuestas específicas (Reher, Dir. 2008). 
De hecho, la importancia de la red familiar en la atracción hacia España de nuevos inmigrantes continúa muy activa en la actualidad (2009-2010), pese a la crisis económico-laboral. Así, los reagrupantes encuestados en la España mediterránea señalan, en proporciones altas, que sí tienen intención de facilitar la llegada a España de otros familiares distintos a la familia ya reagrupada. El $27 \%$ de los reagrupantes africanos contestan que sí harán invitación a emigrar a España a nuevos familiares (34\% en el caso de los que residen en Cataluña), fundamentalmente cuando se trata de padres ( $25 \%$ en relación al conjunto de sus familiares a invitar) y sobre todo de hermanos (39\%), aunque estos últimos alcanzan extremos muy distanciados para los reagrupantes que residen en $\mathrm{Ca}$ taluña (53\%) y para los de Murcia-Almería (25\%), lo que sin duda denuncia las distintas posibilidades de empleo para los nuevos inmigrados familiares que lleguen con la intención de incorporarse al mercado laboral. Los reagrupantes latinoamericanos se muestran más optimistas ante la inmigración de nuevos familiares: un tercio de los reagrupantes dice que sí, con las esperadas diferencias entre los que residen en Cataluña (37\%) y los de Murcia-Almería, con sólo un $24 \%$. Como en el caso de los africanos, los hermanos son siempre los familiares preferidos para esta nueva inmigración, 37\% del total de familiares, seguidos de los padres (25\%).

En conclusión, las redes migratorias constituidas por familiares y amigos son un elemento clave en la inmigración africana y latinoamericana que recibe España, pues tienen importancia decisiva a lo largo del proceso inmigratorio, es decir, son responsables principales en la orientación de los nuevos emigrantes hacia España; continúan actualmente con la intención de atraer a más familiares -pese a la crisis-, especialmente a hermanos en edad laboral, y son, igualmente, los responsables más destacados como «agentes» para buscar empleos para los familiares ya instalados en España, aunque en este caso los amigos se convierten en las principales ayudas para obtener empleo, muy por delante de los familiares, lo que se explica por ser los amigos más numerosos que los familiares y poseer, por tanto, situaciones más variadas a la hora de localizar nuevos empleos para los integrantes de las redes de inmigración, cuestión que se detalla en el epígrafe siguiente.

\subsection{Motivos de la elección de España como país de emigración}

Al llegar a España declaran que buscaban trabajo el 87\% de los actuales reagrupantes africanos encuestados y el $85 \%$ de los latinoamericanos, siempre con la suma de ambos sexos. No obstante, al indicar los motivos que les llevaron a escoger España como país para su emigración (la encuesta admite hasta tres motivos, por lo que se acumulan 526 respuestas entre los africanos y 720 entre los 
latinoamericanos), se mezclan los motivos de «posibilidad de trabajo» señalados directamente, con otros motivos que, a su vez, pueden facilitar o ser decisivos para conseguir la finalidad laboral última.

Así, el motivo "posibilidad de trabajo» es señalado directamente por el $45 \%$ de las respuestas de africanos de ambos sexos y por el 35\% de los latinoamericanos. El segundo motivo de la elección de España para ambos grupos continentales es la «presencia de familiares y/o conocidos» en España - $18 \%$ de las respuestas de los africanos y $23 \%$ de los latinoamericanos- pues los familiares y sobre todo los amigos ya residentes en España son el medio mayoritario para captar nuevos empleos para el grupo. En efecto, según los reagrupantes encuestados, los familiares y amigos -estos últimos mucho más numerosos- fueron el medio para obtener el trabajo actual (2009-2010) de más de la mitad de los reagrupantes africanos y latinoamericanos ocupados. En el caso de los cónyuges, los amigos y familiares encontraron el trabajo actual para el 60\% de los africanos y latinoamericanos, y en el caso de sus hijos reagrupados con empleo en 2009-2010, los amigos y familiares les proporcionaron el trabajo al 76\% de los africanos y al $64 \%$ de los latinoamericanos. Para los totales familiares ocupados en 2009-2010, 343 africanos y 686 latinoamericanos, el medio para obtener sus empleos corresponde, en el caso de los africanos, un 38\% a los amigos y un 20\% a los familiares, mientras que, entre los latinoamericanos, tales proporciones se elevan al 49\% y 13\%, respectivamente. Queda, pues, patente la eficiencia de las redes migratorias para localizar trabajos para el grupo respectivo, con resultados muy similares entre los africanos y latinoamericanos.

En el resto de motivos aducidos por los reagrupantes encuestados para la elección de España como destino emigratorio, destacan dos que, por razones obvias, alcanzan importancia diferente entre africanos y latinoamericanos: así, las afinidades culturales son señaladas por el 18\% de los reagrupantes latinoamericanos, frente al 5\% de los africanos; por el contrario, la cercanía geográfica al país de origen es señalada como motivo de la elección de España por el 11\% de las respuestas de los africanos, por sólo el 1\% de los latinoamericanos.

Motivo de atención merecen las facilidades de entrada y/o permanencia en España que, en su momento, los reagrupantes dicen haber encontrado, pues estos motivos fueron importantes en la elección de España para el 12\% de los africanos y el 11\% de los latinoamericanos. La accesibilidad al sistema escolar y universitario de España, así como el rechazo sufrido en las fronteras de terceros países de inmigración, sólo son citados por los reagrupantes de forma testimonial para elegir España como su país de emigración, lo que pone de relieve el carácter casi exclusivamente laboral de los inmigrantes estudiados, y que España ha sido país de primera opción para estos emigrantes. 
Las notables diferencias que se registran entre los residentes en Cataluña litoral y en Murcia-Almería en casi todos los indicadores tratados en la encuesta que analizamos, también aparecen -aunque de forma limitada- en los motivos que llevaron a los reagrupantes a escoger España como país de emigración. Así, la «posibilidad de trabajo» parece más clara para los que residen en MurciaAlmería - $50 \%$ entre los africanos, $42 \%$ en los latinoamericanos- que para los que viven en Cataluña - $41 \%$ y 34\%, respectivamente-, lo que es una contradicción aparente dada la limitación sectorial en la agricultura que ofrecen las provincias del sur, y que, además, es la actividad que los inmigrados juzgan menos adecuada para sus proyectos emigratorios. Entre las explicaciones posibles a esta aparente contradicción, cabe señalar que en Murcia-Almería cuando hace años llegaron los actuales reagrupantes (Gozálvez et al., 2012b), sin duda encontraron una oferta de empleo en la agricultura abundante y sin competencias de otros trabajadores, tanto por la retirada de los españoles de esta actividad, como por ser el inicio de la llegada masiva de los trabajadores extranjeros; además, el trabajo agrícola en estas explotaciones minifundistas sin duda era el más adaptado tanto a los que accedían al empleo de forma irregular, como a los trabajadores con bajo nivel de estudios y/o con dificultades en el uso del idioma español, es decir, africanos y latinoamericanos andinos, los más representados en MurciaAlmería.

Como exponente de la insatisfacción del trabajo agrícola para alcanzar los objetivos económicos y sociales de los trabajadores extranjeros, los datos de la encuesta que analizamos muestran una tasa de movilidad interregional -entre la fecha de llegada y la actualidad- mucho mayor entre los reagrupantes asentados en Murcia-Almería que entre los que residen en Cataluña: para los primeros, las tasas de esta movilidad afectan al 21\% de los reagrupantes africanos y al 31\% de los latinoamericanos; para los residentes en Cataluña, las tasas de movilidad interregional se quedan en el 13\% y 10\%, respectivamente, sin duda por la mayor satisfacción que les produce su trabajo en Cataluña y, por consiguiente, no tienen necesidad de realizar migraciones interregionales en busca de nuevas oportunidades de trabajo.

La «colonización» más reciente por parte de los trabajadores extranjeros de Murcia-Almería respecto a Cataluña, se refleja en la distinta importancia que alcanza en cada uno de estos territorios la «presencia de familiares y amigos» como motivo para elegir España como destino emigratorio de los futuros reagrupantes: en Cataluña esta causa es aducida por el 19\% de los africanos y el $23 \%$ de los latinoamericanos, mientras que para los reagrupantes que residen en Murcia-Almería tal motivo desciende al 13\% y 19\% de los respectivos grupos continentales. 


\section{LA REGULACIÓN LABORAL DE LOS INMIGRADOS EN SU PRIMER TRABAJO EN ESPAÑA Y EN LA ACTUALIDAD (2009-2010)}

Todos los estudios que abordan la regulación laboral de los inmigrados (Cohen; Berriane et al., 2011. Reher et al., 2008), concluyen en señalar que ésta presenta una acusada situación precaria, especialmente cuando acceden a su primer trabajo en España. Esta situación responde, por una parte, a la debilidad de la oferta laboral en España, bien visible en las altas tasas de paro que se registran en el país desde los años 1980, y sobre todo, debido a los disparatados incrementos de nuevas entradas de extranjeros en busca de empleo (Gozálvez, 2012a), casi siempre sin contar con contratos de trabajo en origen.

La información de la encuesta que ahora se estudia, la suministraron los reagrupantes familiares en 2009-10, y está referida a ellos mismos y también a sus familiares reagrupados que conviven con él/ella en la España mediterránea. La regulación laboral de los reagrupantes se estudia en dos etapas significativas de su proceso inmigratorio: en su primer trabajo en España, y en la actualidad, ahora referida tanto para los mismos reagrupantes como para sus cónyuges y sus hijos. Por motivos estadísticos, las cifras sólo se ofrecen para los dos sexos juntos. Como ya se indicó, por definición las cifras de reagrupantes ocupados son más altas cuando están referidas al primer trabajo -336 africanos, 444 latinoamericanos-, pues el paro laboral actual reduce los reagrupantes ocupados a 216 africanos y a 331 latinoamericanos (fig. 2).

Figura 2. Regulación laboral de los reagrupantes en la España mediterránea: a, primer trabajo en España, y b, trabajo actual, en \%. Ambos sexos.
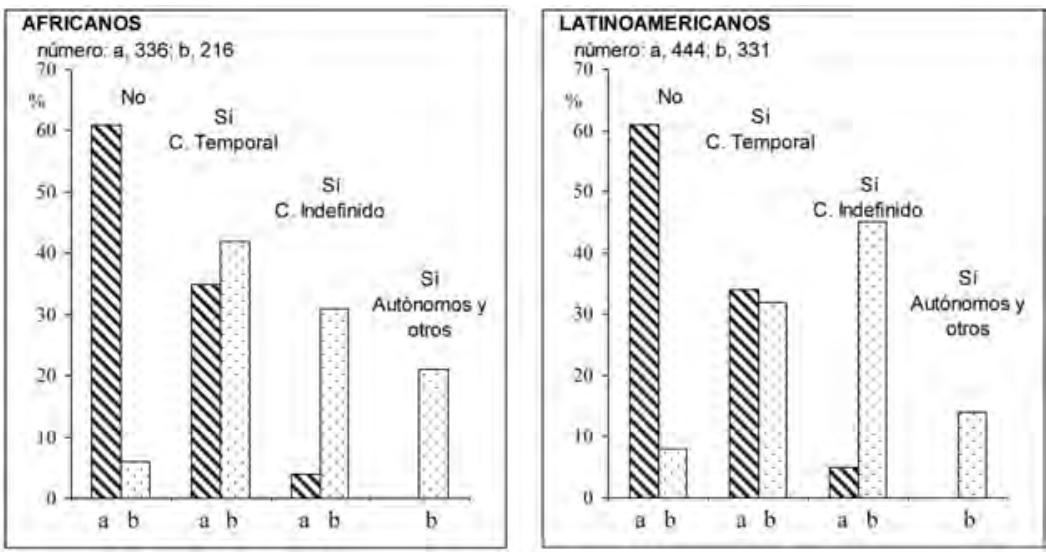

Nota: las cifras absolutas indican el número de encuestados que respondieron a la pregunta incluida en el título de la figura.

Fuente: Encuesta sobre Reagrupación Familiar en la España Mediterránea (ERFEM), 2009-2010, Proyecto CS02008-01796 (Ministerio de Ciencia e Innovación), citado en nota 1. Elaboración propia 


\subsection{La regulación laboral de los reagrupantes}

La generalizada precariedad laboral de los reagrupantes en su primer trabajo en España, tiene una significativa manifestación en su carencia de contrato laboral, pues esta situación afectaba al $61 \%$ tanto de los africanos encuestados como de los latinoamericanos (fig. 2). Esta tasa apenas varía en cada una de las tres áreas territoriales, Cataluña litoral, Comunidad Valenciana y Murcia-Almería; no obstante, la carencia de contrato laboral casi siempre tiene sus menores tasas en Cataluña, sobre todo para los africanos (57\%), mientras los latinoamericanos alcanzan la peor situación en Murcia-Almería, donde el 72\% de los que ahora viven allí no tuvo contrato en su primer trabajo en España.

La llegada a España del inmigrante sin contrato laboral provoca, entre otras razones, que los contratos indefinidos para su primer trabajo en España sólo alcancen al 4\% de los africanos y al 5\% de los latinoamericanos. No obstante, en los territorios estudiados de la España mediterránea existe gradación entre Cataluña, con un 7-6\%, y Murcia-Almería, con un 1-3\% para cada grupo de nacionalidades, respectivamente. Estas bajas proporciones de contratos fijos para el primer trabajo en España, probablemente reflejen el alcance real -dentro de la inmigración laboral total- de los cupos de contratación laboral en origen establecidos en 1993 por el Ministerio de Trabajo de España. La diferencia entre carencia de contrato (61\%) y contrato fijo corresponde a los inmigrantes que tuvieron contrato temporal (35\%) en su primer trabajo en España. En cualquier caso, hay que resaltar la igualdad entre africanos y latinoamericanos en la regulación laboral precaria de su primer trabajo en España, pese al desigual capital personal para el trabajo que aportan cada uno de estos dos grupos continentales, mucho más positivo (lengua, instrucción, cultura, ...) entre los latinoamericanos.

De acuerdo con sus deficientes condiciones de regulación laboral, el primer trabajo en España de los reagrupantes encuestados tuvo una duración muy limitada, sobre todo entre los africanos, para quienes el $40 \%$ de sus primeros trabajos duró menos de seis meses, y sólo un tercio superó el año de duración, de los que el 9\% ha tenido continuidad hasta la actualidad (2009-2010). Los latinoamericanos, mucho mejor preparados para trabajar en España (dominio del idioma, mejor nivel de instrucción, cultura afín), alcanzaron mayor estabilidad en su primer trabajo, pues una duración inferior a seis meses afectó «sólo» al 30\% de los primeros trabajos, mientras destacan los que alcanzaron duración superior a un año, el $43 \%$ del total, de los que el 10\% ha perdurado hasta la actualidad. En cualquier caso, los trabajos más inestables son los que fueron iniciados por los reagrupantes que actualmente residen en Murcia-Almería, lo que es acorde tanto a la estructura laboral ofertada en esta área, dominada por el trabajo en la agricultura minifundista, como al propio inmigrante que no desea trabajar en el 
sector agrario, según se atestigua en la serie de encuestas realizadas desde 1991 por este equipo de investigación.

En 2009-2010, cuando se realizan las encuestas, ya en plena crisis económico-laboral, la regulación laboral para los que han conseguido estatus de reagrupantes ha cambiado sustancialmente en positivo, respecto a la que tuvieron como inmigrantes en su primer trabajo en España; no obstante, la precariedad laboral continúa siendo muy visible, ahora mediante sus elevadas tasas de paro, como se verá. Los reagrupantes que en 2009-10 están ocupados sin contrato laboral -por haber perdido el que tenían como reagrupantes- son el 6-8\% de los africanos y latinoamericanos, respectivamente, mientras se mantienen tasas del $30-40 \%$ de contratados temporales. La mejora sustancial en la regulación laboral se debe, pues, al aumento de los que han conseguido contratos indefinidos, que ha beneficiado sobre todo a los latinoamericanos, con el $45 \%$ de su total de ocupados, frente al 31\% de los africanos. Atención especial merece la categoría de regulación laboral de autónomos, que en 2009-10 afecta sobre todo a los africanos, con el 19\% de los ocupados -11\% los latinoamericanos-, explicables por la dedicación al comercio autónomo, esencialmente ambulante, ejercido ante todo por los varones africanos; en el comercio por cuenta propia trabaja el 21\% de los africanos ocupados, proporción que sólo es sobrepasada por los que tienen empleo en la agricultura (24\%).

\subsection{La regulación laboral actual (2009-10) de los miembros de las familias reagrupadas}

Los miembros de las familias reagrupadas en la España mediterránea que actualmente están ocupados suman en total 361 africanos y 678 latinoamericanos. Entre los africanos, el 60\% de los ocupados son reagrupantes, mientras el $40 \%$ restante se reparte entre cónyuges (19\%) e hijos (21\%). En las familias latinoamericanas, los reagrupantes ocupados suman el 49\%, y del resto, el 30\% son cónyuges y el $21 \%$ son hijos.

Tal como se muestra en la figura 3, la regulación laboral, en cualquiera de las situaciones, tiene tasas más desfavorables entre los cónyuges y los hijos que entre los reagrupantes. Entre los que sí tienen regulación laboral, la situación es mucho más negativa para los africanos -más contrato temporal, menos contrato indefinido, más autónomos precarios- que para los latinoamericanos.

Los miembros de las familias que trabajan actualmente sin contrato laboral afectan menos al grupo de los reagrupantes, pues todos han tenido antes, por definición, una situación positiva. Por el contrario, la peor situación entre los que trabajan sin contrato corresponde a los/las cónyuges, sobre todo africanos (22\% de su total), que son fundamentalmente mujeres (Gozálvez et al., 2012b), muy 
vinculadas al trabajo en los hogares. En cualquier caso, el trabajo sin contrato alcanza tasas más altas entre los latinoamericanos -excepto para los cónyuges-, lo que puede reflejar el menor control para este grupo por las leyes de inmigración (Gozálvez et al., 2005: 150-153).

Fig. 3. Regulación laboral del trabajo actual (2009-2010) del reagrupante y de los miembros de su familia en la España mediterránea, en \%. Ambos sexos.

a, reagrupante; b, cónyuge; c, hijos; d. conjunto de familiares.
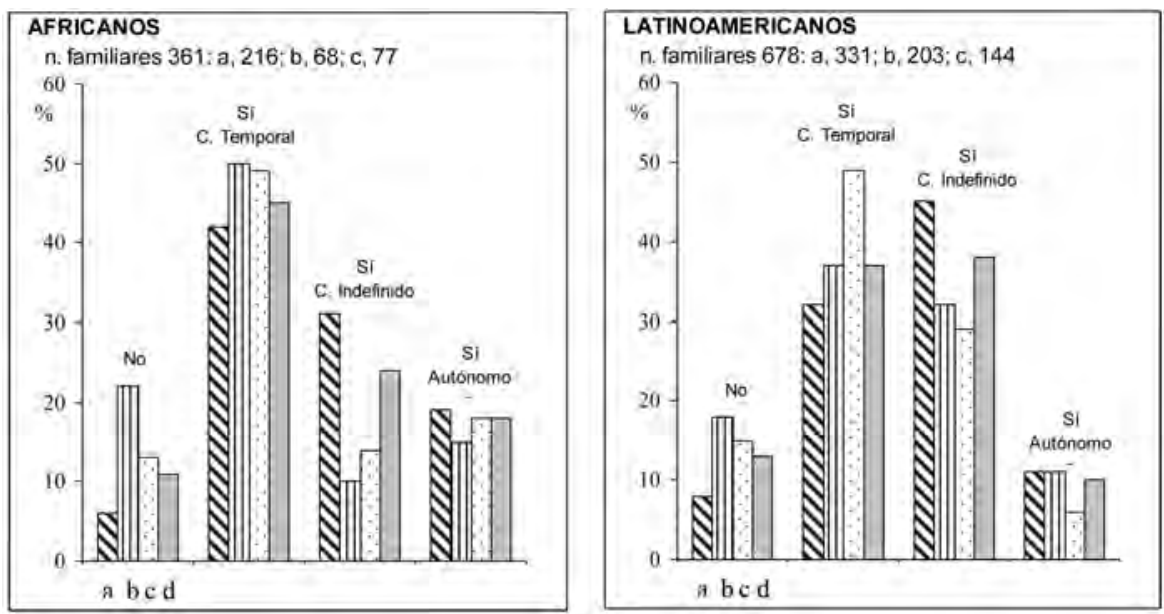

Nota: las cifras absolutas indican número de familiares.

Fuente: ERFEM, 2009-2010. Elaboración propia

De los que sí tienen regulación laboral, los africanos muestran mayor precariedad: así, los distintos grupos familiares de este colectivo tienen tasas de contratos temporales mucho más altas que los latinoamericanos, con la excepción del grupo de hijos, pues el contrato temporal afecta a la mitad de los jóvenes de ambos grupos de nacionalidades. Las diferencias máximas entre africanos y latinoamericanos se encuentran en los que tienen contrato indefinido, con proporciones muy superiores en los latinoamericanos, bien sean reagrupantes, cónyuges o hijos (fig. 3). Para el conjunto de los miembros de las familias, tienen contratos indefinidos el 24\% de los 361 ocupados africanos y el 38\% de los 678 latinoamericanos; la mayor estabilidad laboral de los segundos sin duda responde a su mejor bagaje formativo y a su cultura afín a la de los españoles, tal como lo declaran expresamente los empresarios que emplean a inmigrados de estos grupos de nacionalidades (Gozálvez et al., 2006).

Finalmente, el grupo de ocupados autónomos alcanza entre los africanos tasas (18\% de los ocupados familiares) que casi doblan a las de los latinoamerica- 
nos (10\%). En realidad, estos autónomos subrayan la mayor precariedad laboral de los africanos, pues son fundamentalmente ocupados en el comercio propio, tanto ambulante, como estable, en parte étnico.

En conclusión, es evidente que los africanos y latinoamericanos que han conseguido reagrupación familiar han mejorado sustancialmente su estabilidad laboral, sobre todo en lo que concierne al trabajo sin contrato laboral, que ha pasado del 61\% de estos inmigrantes en su primer trabajo en España, al 6-8\% para cada colectivo en 2009-10. Además, los contratos indefinidos han evolucionado desde el 4-5\% en el primer trabajo, hasta el 31-45\% en 2009-10 para africanos y latinoamericanos, respectivamente. Sin embargo, la precariedad laboral en la contratación continúa muy vigente, pues en 2009-10 la suma de contratos temporales y de autónomos afecta al $61 \%$ de los reagrupantes africanos y al $43 \%$ de los latinoamericanos. Estas últimas proporciones ilustran bien la mayor precariedad laboral de los africanos, casi forzada por sus graves deficiencias en el dominio del idioma y en su bajo nivel de instrucción (Gozálvez et al., 2012b). Por otra parte, como veremos, esta precariedad laboral en la contratación se «complementa» mucho más gravemente con las tasas de paro de los reagrupantes, que en 2009-10 alcanza al $36,4 \%$ de los africanos y al $27,3 \%$ de los latinoamericanos, cuando la media nacional se situaba en el 19,6\%, según la Encuesta de Población Activa (INE).

\section{EVOLUCIÓN DE LA ESTRUCTURA OCUPACIONAL DE LOS REAGRUPANTES}

La encuesta realizada (2009-10) solicitó información al reagrupante sobre sus empleos en tres momentos diferentes de su proceso inmigratorio en España: primer trabajo en el país, empleo que tenía cuando solicitó la reagrupación familiar, y el trabajo que ejerce en la actualidad (2009-10). Estos tres momentos del ciclo migratorio de los reagrupantes sin duda son relevantes para mostrar las posibilidades laborales reservadas a estos inmigrados dentro de su proceso inmigratorio inicial, y también son significativas para evaluar las posibilidades actuales de su integración y las de su familia reagrupada en la sociedad española. En este último aspecto, la información laboral solicitada al reagrupante se ha ampliado mucho para el momento actual, pues además de la información sobre el propio reagrupante, éste también informa sobre variados aspectos laborales actuales de los miembros de su familia, es decir, del cónyuge y de sus hijos que conviven con él; asimismo, el reagrupante ha facilitado información sobre otros miembros de su familia (progenitores, hermanos, ...) que también conviven con él, aunque este último colectivo es muy reducido (Gozálvez et al., 2012b). La estructura ocupacional actual (2009-2010) de los miembros de la familia extranjera reagrupada en la España mediterránea se estudia en el epígrafe siguiente. 
La información sobre el empleo se ofrece por grandes sectores económicos: agrario, industria, construcción, hostelería, comercio, hogar y otros servicios. Desde el punto de vista territorial, primero se ofrece la información para el conjunto de los reagrupantes africanos y latinoamericanos que residen en la España mediterránea litoral entre Girona y Almería; esta escala permite distinguir el empleo por sexos (fig. 4), pues uno y otro sexo se «apropian» de modo desigual de cada uno de los sectores de empleo; no obstante, en el caso de las reagrupantes africanas el bajo número de las encuestas puede mermar su fiabilidad estadística. En segundo lugar, se ofrece la información para cada una de las tres áreas territoriales donde se han realizado las encuestas: Cataluña litoral, C. Valenciana y Murcia-Almería; en este caso, al disminuir el número absoluto de reagrupantes encuestados por unidad territorial, se ha optado por ofrecer la información laboral evolutiva y por nacionalidades sólo para el conjunto de los dos sexos. Como se verá, la estructura económica existente en cada uno de estos tres territorios indicados, tiene influencia decisiva en la estructura ocupacional de los reagrupantes, diferencias que alcanzan la máxima distancia entre Cataluña litoral y Murcia-Almería. En cualquier caso, existen acusadas diferencias en la estructura de sus empleos entre los reagrupantes africanos y latinoamericanos, que responden a sus distintos «capitales» personales, sobre todo los referidos a su nivel de instrucción, dominio del idioma español y también a sus culturas. Por razones de «definición», cuando el reagrupante encuestado declara su primer trabajo en España y el que tenía cuando realizó su reagrupación familiar, excluyen la existencia de paro, situación laboral que sí se hace notar mucho en el número de reagrupantes que declaran su ocupación actual, lo que se traduce ahora en un número de ocupados menor (fig. 4).

Los reagrupantes encuestados, al ser un colectivo con éxito en su estabilización laboral y residencial en España, han mejorado sustancialmente su regulación laboral inicial, como se ha mostrado, e igualmente han mejorado la estructura de sus empleos. No obstante, los cambios sustanciales de esta estructura son trasvases dentro de los sectores inicialmente «reservados» a esta mano de obra extranjera: agricultura, construcción, hogar y restauración-hostelería. Conquistas significativas de empleo en nuevos sectores económicos más apetecidos y acordes con el proyecto migratorio del inmigrado, sólo se han producido en algunos subsectores terciarios que incluimos en el apartado «otros servicios». Los empleos en agricultura y construcción son los que han experimentado mayores cambios; en la agricultura, la mejora del estatus del inmigrado se ha traducido en una disminución relativa continuada de estos trabajadores, siempre por iniciativa del propio inmigrado 
Figura 4. Evolución de la estructura ocupacional de los reagrupantes en la España mediterránea. En \%, según nacionalidades y sexos.

a, Primer trabajo en España; b, trabajo cuando hizo la reagrupación; c, trabajo actual (2009-2010).
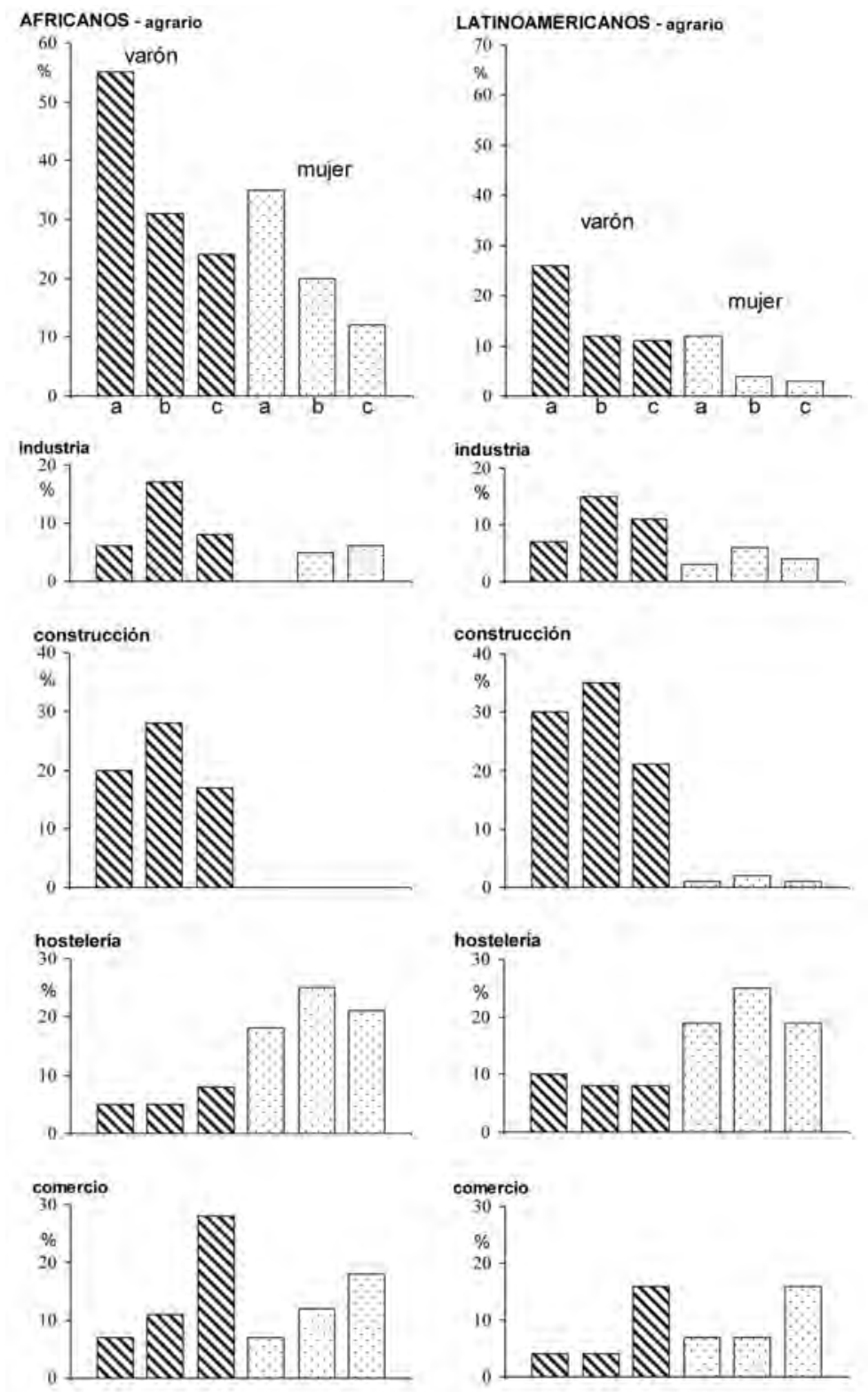

Investigaciones geográficas, $n^{\circ} 58$, pp. 171 - 218 

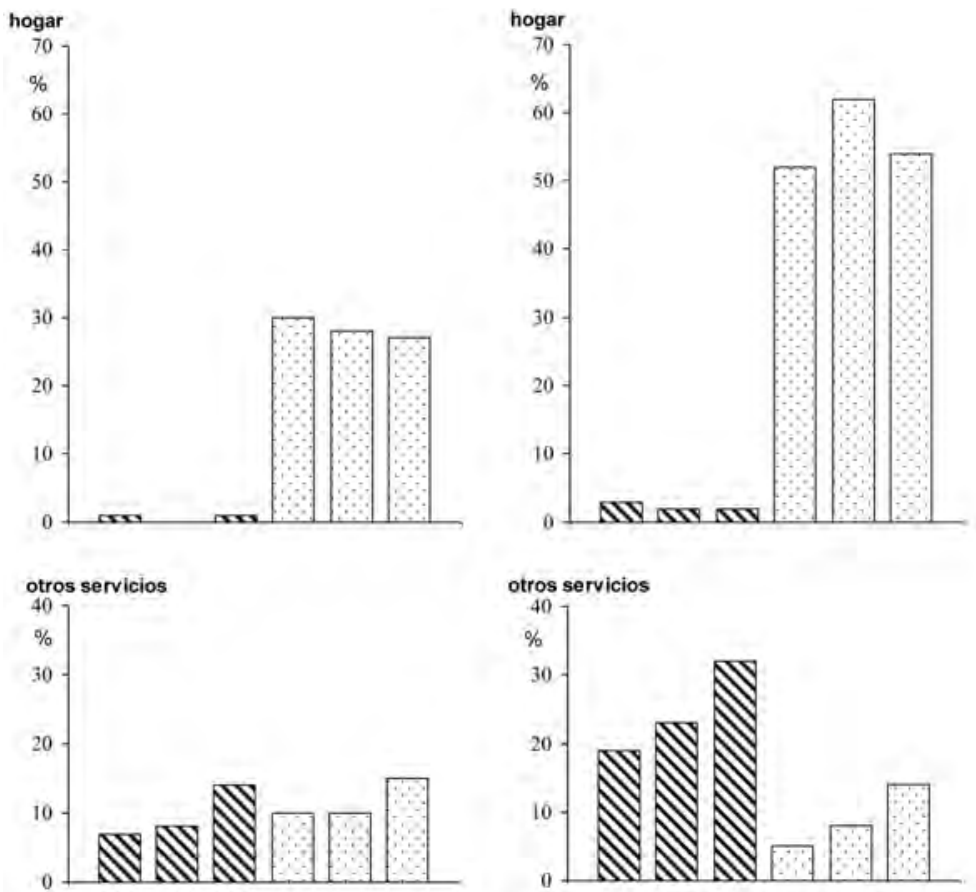

Número total de reagrupantes con trabajo

\begin{tabular}{|r|r|r|r|r|}
\cline { 2 - 5 } \multicolumn{1}{c|}{} & \multicolumn{2}{c|}{ Africanos } & \multicolumn{2}{c|}{ Latinoamericanos } \\
\cline { 2 - 5 } \multicolumn{1}{c|}{} & Varón & Mujer & Varón & \multicolumn{1}{c|}{ Mujer } \\
\hline a & 304 & 40 & 244 \\
\hline b & 301 & 40 & 232 & 197 \\
\hline c & 182 & 33 & 150 & 172 \\
\hline
\end{tabular}

Fuente: ERFEM, 2009-2010. Elaboración propia

al considerar que la agricultura es un sector ocupacional que económica y socialmente no responde a sus expectativas. La construcción sí es un sector económicamente apetecido, por lo que alcanzó su máxima importancia en el empleo de estos extranjeros cuando éstos realizaron su reagrupación familiar, que, por la fecha de realización de la encuesta (2009-2010), sin duda se sitúa mayoritariamente en los años previos al inicio de la actual crisis económico-laboral (2008). Este deterioro económico es la razón de la fuerte pérdida de empleo en este sector en 2009-10, acompañado de una altísima tasa de paro laboral, 38,9\% entre los varones africanos reagrupantes y del $36,7 \%$ entre los latinoamericanos. 
a) El sector agrario adquiere para los inmigrantes africanos de ambos sexos la categoría de máximo «recurso» laboral para el primer empleo en España (fig. 4 y 5), pues a este trabajo acudieron el 55\% de los varones y el $35 \%$ de las mujeres. Entre los latinoamericanos, su primer trabajo en España también estuvo muy vinculado al sector agrario, pues en él trabajaron el 26\% de los varones y el 12\% de las mujeres. Esta «especialización» agraria durante el primer trabajo en España no fue de elección libre del inmigrante, al menos como empleo finalista, sino que vino impuesto por ser el sector de empleo más adaptable a la falta de regulación laboral que en ese primer trabajo padecían los inmigrantes, además de otras motivaciones, como la menor competencia para obtener estos empleos: el 61\% de los reagrupantes africanos y latinoamericanos encuestados manifiestan que carecían de contrato laboral durante su primer trabajo en España. Por parte de los empresarios, asumir riesgos legales -sanciones- cuando se emplea a inmigrantes sin contrato laboral puede explicarse en el sector agrario, entre otras razones, por tratarse de ofertas de trabajo de corta duración en explotaciones agrarias minifundistas y dispersas, vinculadas sobre todo a la siembra o recolección de horticultura o fruticultura.

Por otra parte, el rechazo al trabajo en la agricultura es «histórico» entre los inmigrantes que llegan a España, en alta proporción con origen urbano, tal como ya lo manifestaban los marroquíes encuestados por primera vez entre octubre de 1991 y mayo de 1993 en este mismo espacio de la España mediterránea: de las 498 encuestas que entonces se hicieron a marroquíes residentes, el 45\% trabajaba en el sector agrario, pero declaraban que realizaban este trabajo "por no haber otro» (Gozálvez, dir., 1995: 32-34). Los reagrupantes encuestados en 2009-10 también rechazan el trabajo en el sector agrario, como queda patente en el rápido abandono laboral de este sector por parte del inmigrante cuando se solucionan sus problemas legales de residencia y trabajo en España. En efecto, tal abandono ya se ha producido cuando el inmigrante realiza su reagrupación familiar, tal como se lee en la fig. 4, siempre, claro está, que haya posibilidad de empleo en otro sector económico, tal como se observa en la fig. 5: el abandono del sector agrario entre el primer trabajo y el trabajo que tenían cuando realizaron la reagrupación familiar es muy alto en Cataluña litoral y en la C. Valenciana, pero muy modesto en Murcia-Almería; es decir, en Cataluña los varones africanos empleados en el sector agrario pasan del 40\% de su total al 10\%, en la C. Valenciana del 52\% al 18\%, pero en Murcia-Almería la evolución es del $82 \%$ al $69 \%$. La aceptación del trabajo agrario en proporciones tan 
altas en Murcia-Almería durante todo el proceso migratorio en España, depende, no tanto de la situación legal del trabajador extranjero, si no de la estructura económica local, acentuada por el abandono del trabajo agrario por parte de los trabajadores locales (Pumares y Jolivet, 2011. Gozálvez y López Trigal, 1999).

Entre las causas más determinantes del abandono del trabajo agrario una vez superados los problemas de legalidad de la residencia del inmigrante en España, además de la existencia de trabajos alternativos, también cuentan los salarios insuficientes en el trabajo agrario, sobre todo si éste es itinerante debido al minifundismo de las explotaciones y/o por los calendarios agrícolas; la dureza del trabajo, sobre todo para los inmigrantes de origen urbano; la inadecuación del trabajo agrícola a la cualificación profesional que aportan muchos inmigrantes, etc. Las mayores frecuencias que alcanzan los africanos en el trabajo agrario en relación a los latinoamericanos, sin duda responden, fundamentalmente, al capital personal deficiente aportado por los africanos para acceder a los trabajos ofertados, es decir, menor nivel de instrucción, escaso dominio del idioma español, etc. (Gozálvez et al., 2012b y 2006). La influencia de la actual crisis económico-laboral sin duda es causa del menor descenso de la proporción de ocupados agrarios que se observa en el trabajo actual (2009-10) respecto al que se tenía cuando el inmigrante realizó su reagrupación familiar, pues han disminuido-desaparecido parte de los trabajos alternativos al agrario.

b) La industria y la construcción son ejemplos de sectores apetecidos por los reagrupantes, pues su máxima participación en ellos se alcanza en el momento de realizar la reagrupación familiar, anterior a la crisis que se inicia en 2008, mientras que cuando se hizo la encuesta, ya en época de crisis (2009-10), el reagrupante ha perdido mucho empleo en ambos sectores, singularmente en la construcción, sector situado en el epicentro de la crisis económica. Si Murcia-Almería es el área territorial más especializada en trabajo agrario para los reagrupantes encuestados, sobre todo entre los africanos (fig. 5), Cataluña litoral se especializa en el trabajo en la construcción para este mismo colectivo, pues ya en el primer trabajo en España, pese a los problemas de la falta de contrato, este sector empleaba al 31\% de los reagrupantes africanos que trabajaban en Cataluña. Casi la totalidad del empleo de reagrupantes en la industria, y especialmente en la construcción, es empleo masculino, a diferencia del sector agrario en el que la mujer reagrupante está bien representada, sobre todo las africanas, aunque en este caso las cifras absolutas de encuestadas son reducidas. 
Figura 5. Evolución de la estructura ocupacional de los reagrupantes africanos y latinoamericanos en Cataluña litoral, Comunidad Valenciana y Murcia-Almería. En $\%$, ambos sexos

a, primer trabajo en España; b, trabajo cuando hizo la reagrupación familiar; c, trabajo actual (2009-2010).

\section{Cataluña - Agricultura}
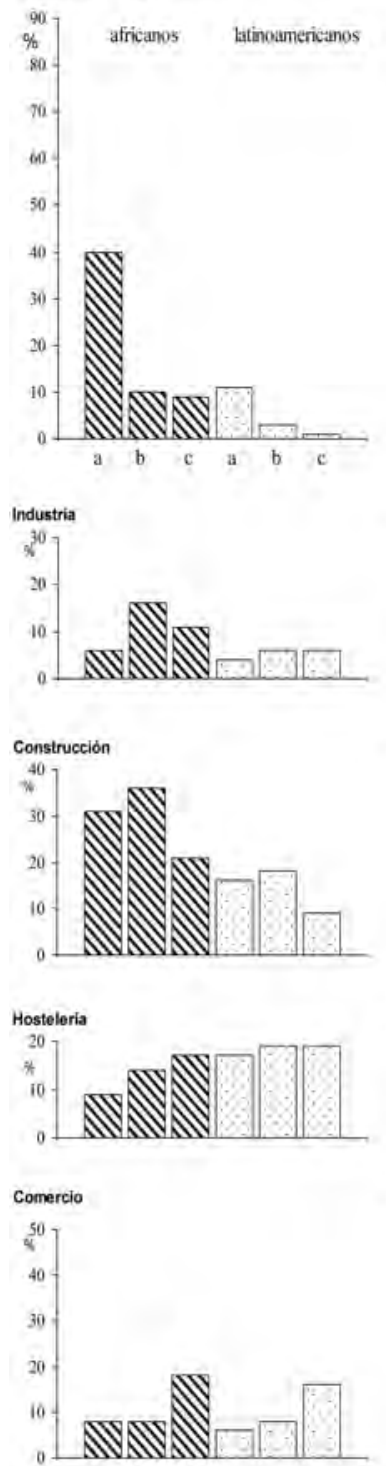

\section{Valenciana - Agricultura}
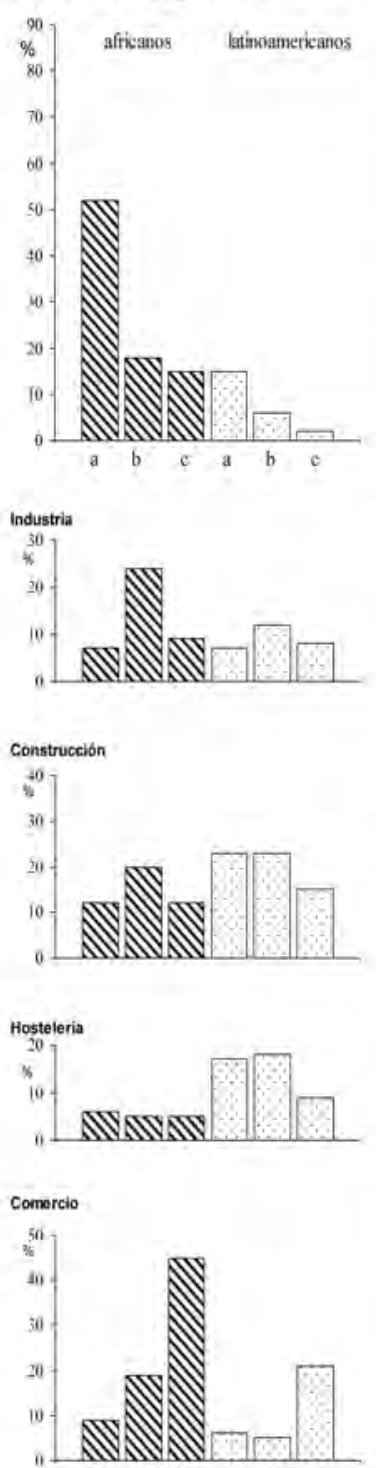
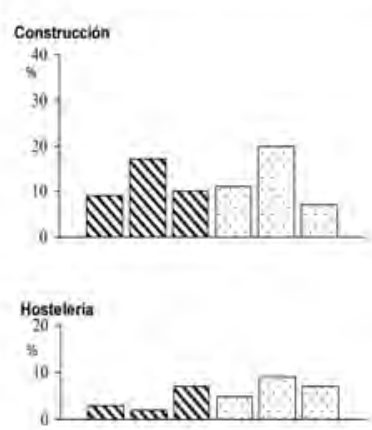

\section{Murcia/Almería - Agricultura}
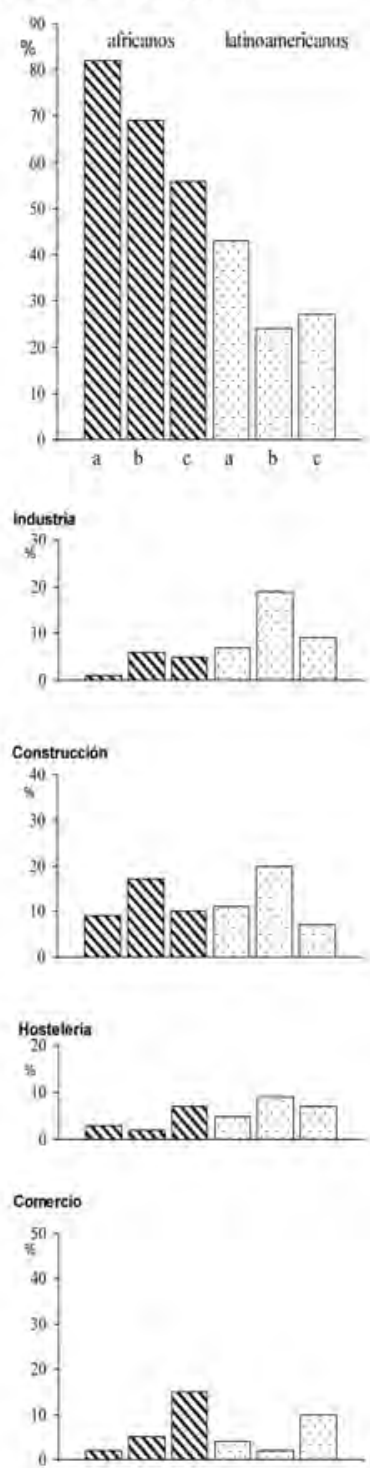

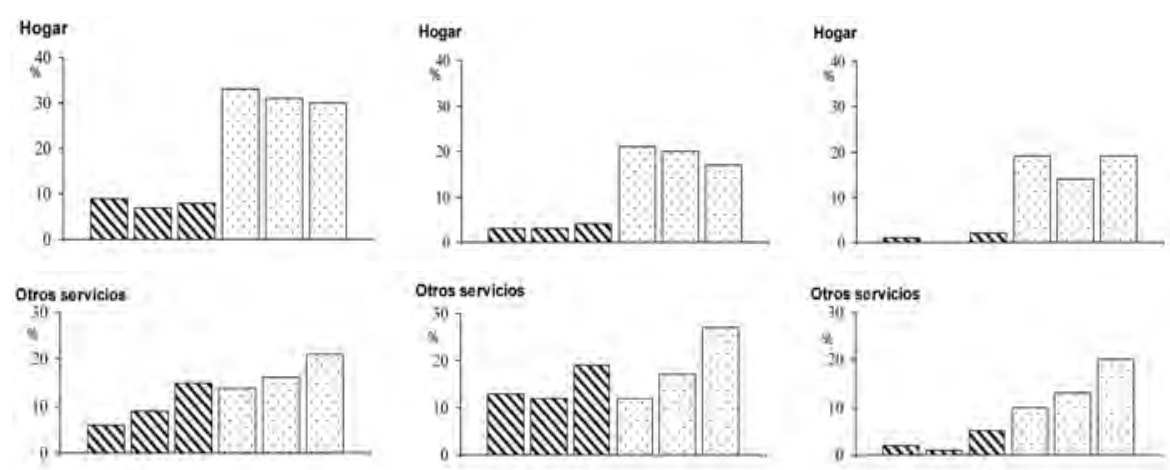

Número total de reagrupantes con trabajo

\begin{tabular}{|r|r|r|r|r|r|r|}
\cline { 2 - 7 } \multicolumn{1}{c|}{} & \multicolumn{3}{c|}{ Africanos } & \multicolumn{3}{c|}{ Latinoamericanos } \\
\cline { 2 - 7 } \multicolumn{1}{c|}{} & \multicolumn{1}{c|}{$\begin{array}{c}\text { Cataluña } \\
\text { litoral }\end{array}$} & $\begin{array}{c}\text { Comunidad } \\
\text { Valenciana }\end{array}$ & $\begin{array}{c}\text { Murcia - } \\
\text { Almería }\end{array}$ & $\begin{array}{c}\text { Cataluña } \\
\text { litoral }\end{array}$ & $\begin{array}{c}\text { Comunidad } \\
\text { Valenciana }\end{array}$ & $\begin{array}{c}\text { Murcia - } \\
\text { Almería }\end{array}$ \\
\hline a & 123 & 121 & 100 & 216 & 133 & 106 \\
\hline b & 120 & 120 & 101 & 199 & 129 & 101 \\
\hline c & 75 & 77 & 59 & 163 & 91 & 68 \\
\hline
\end{tabular}

Fuente: ERFEM, 2009-2010. Elaboración propia

c) La hostelería-restauración es una actividad utilizada mucho más por las mujeres que por los varones reagrupantes, tanto entre las africanas como entre las latinoamericanas (fig. 4); la presencia relativa en este sector es muy parecida en los dos grupos de nacionalidades, al mismo tiempo que se mantiene constante en los tres momentos elegidos del proceso migratorio. Cataluña litoral es el área territorial donde este sector ofrece más empleo relativo a los reagrupantes, aunque en ningún momento del proceso migratorio alcance al 20\% del empleo total (fig. 5); por el contrario, en Murcia-Almería este sector casi excluye a los reagrupantes.

d) El comercio es un sector con participación modesta en el empleo total de los reagrupantes encuestados, tanto según su nacionalidad como para los dos sexos, así como en los tres ámbitos territoriales estudiados (fig. 4 y 5). No obstante, el aspecto más destacable de este empleo es que alcanza destacada importancia relativa en el momento actual (2009-10), lo que es debido fundamentalmente al comercio por cuenta propia, en parte, sin duda, comercio ambulante, pues afecta sobre todo a los varones africanos: en 2009-10, el 21\% de los varones africanos encuestados trabaja en comercio propio, proporción sólo superada por los que se dedican a la agricultura (24\%). Los hechos indicados, es decir, destacado incremento relativo ac- 
tual del empleo en el comercio pero sólo en su modalidad por cuenta propia, producido en ambos grupos de nacionalidades, en ambos sexos y en las tres áreas territoriales estudiadas, sin duda tiene su explicación principal en ser un trabajo que el reagrupante ha buscado como alternativa al paro laboral, y no porque responda a sus aspiraciones económicas y sociales.

e) Los trabajos en el hogar son los de mayor especialización femenina; entre las latinoamericanas es donde este subsector proporciona más empleo, a más de la mitad de todas las reagrupantes que están ocupadas, frente al 30\% de las africanas; además, la importancia relativa de cada colectivo continental se mantiene estable durante las tres situaciones laborales seleccionadas en la encuesta. Las muy altas proporciones de empleo en el hogar entre las latinoamericanas, sin duda responde a su dominio del idioma español y a su cultura afín a la de los españoles. De las especialidades de trabajo en el hogar solicitadas en la encuesta, servicio doméstico y cuidado de ancianos o enfermos, la primera es la que alcanza proporciones más altas, bastante superiores a la mitad de las reagrupantes que trabajan en los hogares.

Cataluña litoral es el área territorial donde es más alta la proporción de empleo en el hogar (fig. 5), con más de un tercio sobre las proporciones que registran las otras dos áreas. La gran aglomeración metropolitana de Barcelona, por su organización laboral espacial que dificulta en mayor medida la atención diaria al hogar, sin duda explica su mayor oferta laboral en los hogares; en este sentido, Cataluña es el área territorial con mayor proporción de empleo en la atención a ancianos y enfermos. Por el contrario, Murcia-Almería, con rentas más bajas, tasas de ocupación femenina menores y ciudades más pequeñas, ofrece las menores proporciones de empleadas en este subsector.

f) El subsector "otros servicios » sin duda es el que mejor refleja el éxito laboral y económico al que aspiran los reagrupantes durante su inicial proceso migratorio en la España mediterránea. Así, de los empleos que incluye este subsector, la mayor parte son los considerados por los propios reagrupantes como « servicios cualificados », entre los que enumeran transporte, camionero, mecánico o seguridad, entre los más repetidos. Esta especialización laboral se concentra fundamentalmente en el trabajo actual (2009-10), es decir, son trabajos sólo conseguidos después de un periodo de residencia en España más o menos prolongado. De acuerdo con el distinto capital personal aportado por los reagrupantes de cada procedencia continental, los varones latinoamericanos son el grupo que ha conseguido mayor presencia en estos empleos relativamente cualificados (fig. 4). El esquema indicado de progreso en la especialización laboral de los reagrupantes se registra con idéntica tendencia en las tres 
áreas territoriales estudiadas (fig. 5), siempre de forma más sólida entre los latinoamericanos, y de modo más sobresaliente en el empleo actual.

g) Sintesis. En 2009-10 los empleos de los reagrupantes africanos y latinoamericanos han cambiado notablemente respecto al primer trabajo en España y al que tenían cuando realizaron la reagrupación familiar. Estos cambios, a) en unos casos -los menos- afectan a la conquista de empleos en subsectores que el inmigrante valora de ascenso social, y también económico (servicios «especializados»); b) los cambios más llamativos son una redistribución de los empleos (absoluta y/o relativa), dentro de los cuatro sectores más poblados de trabajadores inmigrados (agricultura, construcción, hostelería, hogar); en concreto se produce una fuerte disminución relativa de la presencia de africanos y latinoamericanos en el empleo agrario, pues este trabajo es ejercido inicialmente como recurso obligado ante la carencia de regulación laboral de estos trabajadores extranjeros -sobre todo cuando se accede al primer trabajo en España-, ante la falta de otros trabajos alternativos -sobre todo en Murcia-Almería-, o por carencias personales para aspirar a otros trabajos -sobre todo en los africanos (lengua, instrucción)-; c) el tercer cambio es el que se produce en el sector de la construcción, con una fuerte disminución absoluta y relativa de empleo, pero a diferencia del empleo agrario, rechazado por el inmigrante, el de la construcción se produce por la supresión de puestos de trabajo a resultas de la actual crisis económico-laboral, que afecta de modo especial a los trabajadores extranjeros, cuyas tasas de paro laboral prácticamente doblan la media nacional (19\%) en 2009-10. d) La presencia relativa de africanos y latinoamericanos en los sectores de hostelería-restauración y de hogar ha permanecido estable durante su proceso migratorio en España; en ambos casos son trabajos ejercidos fundamentalmente por las mujeres.

Cuadro 1. Evolución sectorial del empleo (\%) de los reagrupantes en la España mediterránea: a, primer empleo en España; b, empleo cuando realizó la reagrupación familiar; c, empleo en 2009-10 (ambos sexos)

\begin{tabular}{|c|c|c|c|c|c|c|c|c|c|c|}
\hline \multirow{2}{*}{$\begin{array}{c}\text { Sector } \\
\text { económico }\end{array}$} & \multicolumn{5}{|c|}{ AFRICANOS } & \multicolumn{5}{c|}{ LATINOAMERICANOS } \\
\cline { 2 - 11 } & $\mathrm{a}$ & $\mathrm{b}$ & $\begin{array}{c}\text { Variación } \\
\text { b/a \% }\end{array}$ & $\mathrm{c}$ & $\begin{array}{c}\text { Variación } \\
\mathrm{c} / \mathrm{b} \%\end{array}$ & $\mathrm{a}$ & $\mathrm{b}$ & $\begin{array}{c}\text { Variación } \\
\text { b/a \% }\end{array}$ & $\mathrm{c}$ & $\begin{array}{c}\text { Variación } \\
\text { c/b \% }\end{array}$ \\
\hline I & 53 & 30 & -43 & 22 & -27 & 19 & 8 & -58 & 7 & -12 \\
\hline II & 23 & 41 & +78 & 22 & -46 & 23 & 31 & +35 & 17 & -45 \\
\hline III & 24 & 29 & +21 & 56 & +93 & 58 & 68 & +17 & 76 & +12 \\
\hline
\end{tabular}

Fuente: ERFEM, 2009-10 (Encuesta de Reagrupación Familiar en la España Mediterránea). Proyecto CS02008-01796 citado en nota 1. Elaboración propia 
Como se comprueba en el cuadro 1, aunque africanos y latinoamericanos tienen presencias diferentes en los repartos sectoriales de sus empleos en cada uno de los tres momentos estudiados, lo que sin duda responde fundamentalmente a las distintas capacidades aportadas por uno y otro colectivo, las tendencias generales de evolución del reparto sectorial de los empleos de africanos y latinoamericanos caminan en el mismo sentido a lo largo de su proceso migratorio vivido en España.

En efecto, la generalizada falta de regulación laboral inicial en ambos colectivos, doblada en el caso de los africanos por sus deficiencias en formación y en idioma español, se traduce en su forzado empleo agrario al acceder a su primer trabajo en España, con tasas que casi triplican a las de los latinoamericanos. Conseguida la necesaria regularización residencial y laboral para realizar la reagrupación familiar, los mayores trasvases sectoriales, medidos en cifras relativas, se producen tanto en africanos como en latinoamericanos, desde el empleo en el sector primario (agricultura) al empleo en el secundario (construcción), mientras el aumento de presencia en el sector terciario es el menor para ambos grupos de reagrupantes. Las variaciones entre el momento en que realizaron la reagrupación familiar y la actualidad (2009-10), ya en plena crisis, están protagonizadas por la destrucción del empleo en la construcción (cuadro 1), con -45\%, mientras continúa el abandono del indeseado trabajo agrario. El sector terciario es el único que aumenta en tiempos de crisis, en unos casos con empleos poco rentables pero sustitutivos del paro laboral, como es el comercio por cuenta propia (presumiblemente ambulante), sobre todo entre los varones africanos, mientras en otros casos se alcanzan empleos mejor remunerados -camioneros, seguridad, etc.-, especialmente por parte de los varones latinoamericanos. No obstante, el efecto más importante de la crisis actual se traduce en altísimas tasas de paro laboral, 38,9\% entre los varones africanos y de 36,7\% entre los latinoamericanos, aunque el paro entre las mujeres queda en tasas de $17,5 \%$ y $16,5 \%$, respectivamente, pues sus empleos mayoritarios, los trabajos en el hogar y en la hostelería-restauración, sufren mucho menos la crisis actual.

En resumen, el sector agrario parece que en ningún caso es aspiración laboral de los inmigrantes; el sector secundario (industria y construcción) es, por el momento, el más acorde a las aspiraciones salariales de ambos colectivos de reagrupantes, aunque la construcción es el único subsector que ha ofrecido empleo cuantioso a los inmigrados en situación de crecimiento económico del país; el sector terciario, con subsectores muy heterogéneos en posibilidades salariales y en aspiraciones, muestra crecimientos ininterrumpidos, aunque de signos económicos muy diferentes de acuerdo con las potencialidades frente al trabajo que aportan los reagrupantes africanos y latinoamericanos. 


\section{LA ESTRUCTURA DEL EMPLEO ACTUAL (2009-10) EN LAS FAMILIAS DE INMIGRANTES REAGRUPADAS}

Los reagrupantes africanos y latinoamericanos encuestados han informado sobre sus empleos actuales y sobre los de cada uno de los miembros de su familia que residen con él en la España mediterránea, es decir, cónyuges, hijos y otros miembros (progenitores, hermanos, etc.), estos últimos siempre muy reducidos (fig. 6).

Los reagrupantes son siempre el grupo familiar más numeroso entre los que disponen de empleo, sobre todo en las familias africanas; en este colectivo continental los reagrupantes representan el 59\% de todos los familiares con empleo (362), mientras en las familias latinoamericanas esta proporción cae al 45\% de un total de 720 ocupados. Estas diferentes proporciones que alcanzan los reagrupantes se explican por el mayor número de ocupados entre los cónyuges latinoamericanos, pues éstos son el $28 \%$ de todos los ocupados familiares, frente al $17 \%$ entre los africanos. El predominio masculino en la inmigración total africana, y el femenino en la latinoamericana, también se manifiesta en la distribución por sexo de los reagrupantes y sus cónyuges con empleo: de la suma de estos dos grupos familiares, los varones africanos son el $72 \%$ de su total, frente al 42\% entre los latinoamericanos, aunque en la alta proporción masculina africana, también influye la menor tasa de activos entre las cónyuges. Finalmente, los hijos con empleo en las familias africanas y latinoamericanas mantienen la misma proporción, 20\%, en ambos grupos de nacionalidades; esta baja proporción que alcanzan los hijos con empleo que viven con el reagrupante, responde a la juventud de sus padres (Gozálvez et al., 2012 b), por lo que sus hijos son mayoritariamente menores de edad, así como a la dificultad generalizada de incorporación de los jóvenes al empleo.

La figura 6 ofrece la distribución actual (2009-10) de los grupos familiares con empleo en grandes sectores económicos: agricultura, industria, construcción, hostelería-restauración, comercio, hogar y otros servicios. Para los reagrupantes y cónyuges el empleo se diferencia por sexo, mientras para el resto de grupos, debido a sus menores valores absolutos, sólo se ofrecen estadísticas para la suma de los dos sexos. Como se indicó, el número de los que tienen empleo actualmente en los distintos grupos familiares, está muy disminuido a consecuencia del elevado paro laboral que provoca la actual crisis económico-laboral: con un paro medio para España de 19,6\% (en 2009-10), en las familias de los africanos encuestados el paro oscila entre el 35\% para los reagrupantes y $42 \%$ para cónyuges e hijos; entre las latinoamericanas, el paro es más bajo y más homogéneo entre los grupos familiares, entre el 26\% para los hijos y el 30\% para los cónyuges; estas diferencias entre africanos y latinoamericanos sin duda alertan sobre sus distintas posibilidades actuales de integración económica. 
Figura 6. Estructura ocupacional en 2009-2010 de los miembros de las familias reagrupadas en la España mediterránea, en \% del total de cada grupo familiar y sexo.

1. Reagrupantes (varón, mujer, ambos); 2. Cónyuges (varón, mujer, ambos); 3. Hijos (ambos sexos); 4. Total familiares (ambos sexos)

AFRICANOS - agricultura

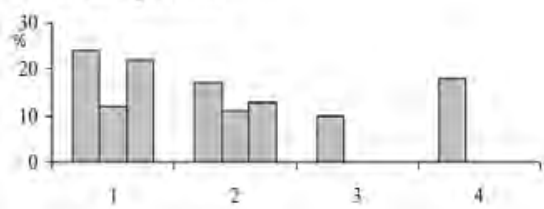

industria

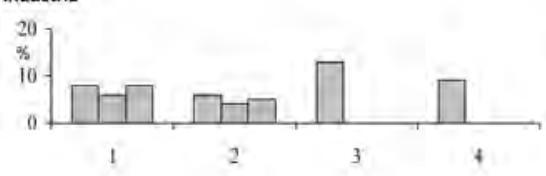

construcciòn

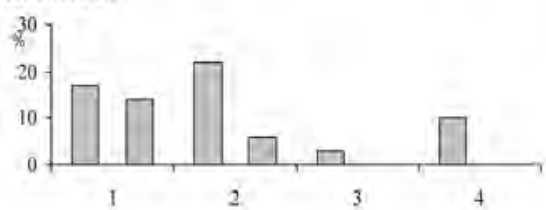

hosteleria

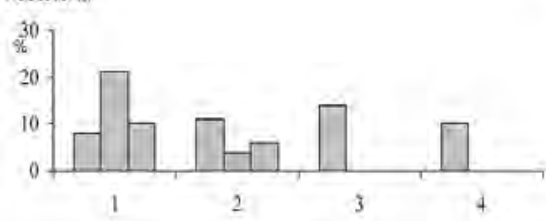

comercio

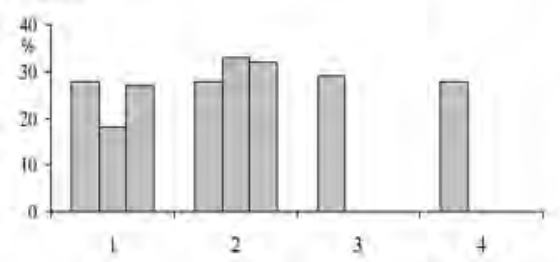

LATINOAMERICANOS - agricultura

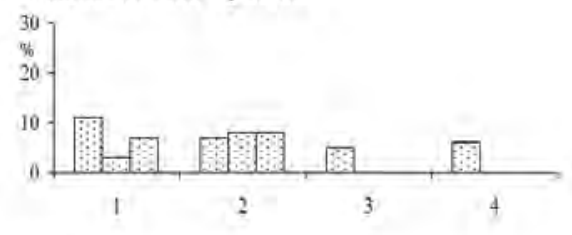

industria

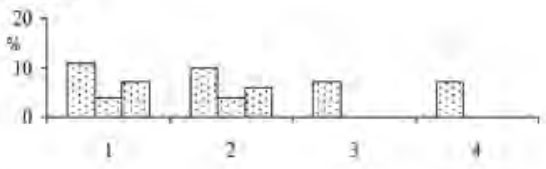

construcción

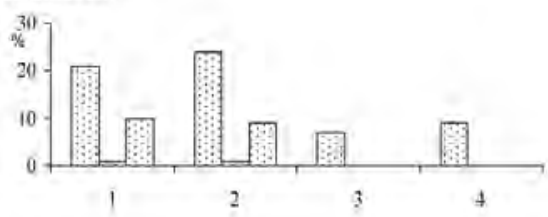

hosteleria

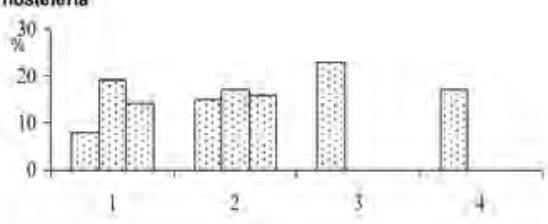

comercio

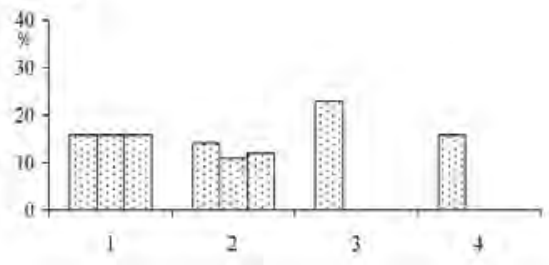



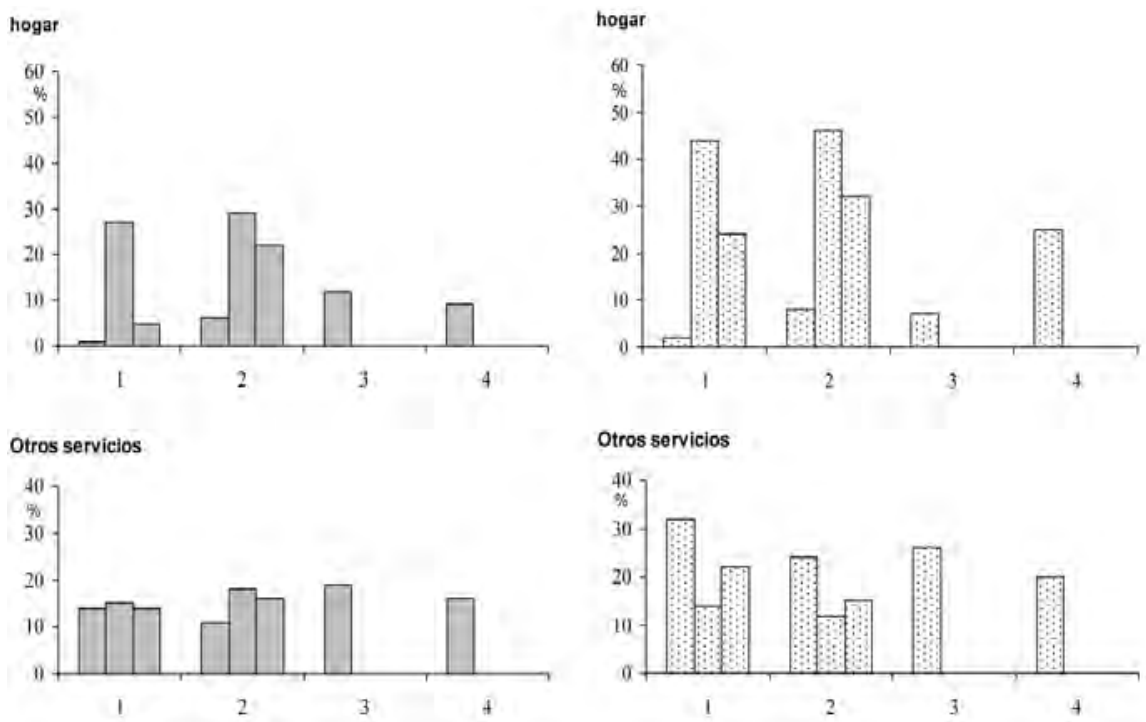

Número total de familiares con trabajo

\begin{tabular}{|c|r|r|r|r|r|r|r|r|r|r|}
\cline { 2 - 10 } \multicolumn{1}{c|}{} & \multicolumn{4}{c|}{ Africanos } & \multicolumn{5}{c|}{ Latinoamericanos } \\
\cline { 2 - 9 } & $\begin{array}{c}\text { Reagru- } \\
\text { pantes }\end{array}$ & $\begin{array}{c}\text { Cónyu- } \\
\text { ges }\end{array}$ & Hijos & Otros & $\begin{array}{c}\text { Total } \\
\text { familiar }\end{array}$ & $\begin{array}{c}\text { Reagru- } \\
\text { pantes }\end{array}$ & $\begin{array}{c}\text { Cónyu- } \\
\text { ges }\end{array}$ & Hijos & Otros & $\begin{array}{c}\text { Total } \\
\text { familiar }\end{array}$ \\
\hline Varón & 182 & 18 & & & & 150 & 72 & & & \\
\hline Mujer & 33 & 45 & & & & 172 & 130 & & & \\
\hline $\begin{array}{c}\text { Ambos } \\
\text { sexos }\end{array}$ & 215 & 63 & 72 & 12 & 362 & 322 & 203 & 148 & 47 & 720 \\
\hline
\end{tabular}

Fuente: ERFEM, 2009-2010. Elaboración propia

De acuerdo con lo mostrado en el apartado anterior sobre la evolución sectorial del empleo en los reagrupantes, el empleo actual del reagrupante y sus familiares queda muy influenciado negativamente por la crisis económica, pues además de tasas extremas en el paro laboral, también se produce pérdida importante de empleos con remuneración satisfactoria para los inmigrados (construcción), aumento de empleos «refugio», sobre todo en el comercio por cuenta propia (ambulante), o trabajo irregular, sin contrato laboral, según se explicó en capítulo anterior.

a) El sector agrario continúa siendo en 2009-10 una «especialización» para los africanos, con el 18\% de todos sus empleos familiares, proporción sólo superada por el 28\% de los que trabajan en el comercio, sobre todo por cuenta propia (19\%). No obstante, esta especialización agraria está alimentada sobre todo por los varones reagrupantes y cónyuges (fig. 6); por el contrario, las menores proporciones de sus hijos en este sector, 
muestra con claridad que el trabajo agrario está lejos de sus aspiraciones económicas y sociales (por sus menores ingresos, a resultas del frecuente empleo itinerante en pequeñas explotaciones y/o por los calendarios agrícolas; así como por la dureza física de este trabajo).

Entre los familiares latinoamericanos reagrupados, con mejores niveles de instrucción y dominio del idioma español, el trabajo agrario actual se reduce al 6\% del total de sus empleos, es decir, es el sector con menos empleo familiar, mantenido casi totalmente por reagrupantes y cónyuges, sobre todo andinos, que quedarían como «testimonio» de las inmigraciones iniciales; el grupo de hijos que trabajan en la agricultura es testimonial, sólo el 5\% de los que tienen empleo, de acuerdo a sus mayores posibilidades frente a los africanos para rechazar este trabajo.

b) La industria se muestra como sector en crisis para el empleo de todos los grupos familiares, aunque destaquen ligeramente (algo más del 10\% del empleo) los varones latinoamericanos reagrupantes y cónyuges, así como el grupo de los hijos africanos.

c) La construcción, pese a la crisis actual, conserva notable presencia relativa en el empleo de los varones reagrupantes y cónyuges, tanto africanos como latinoamericanos, con proporciones de sus empleos que suelen sobrepasar el 20\% de sus totales, aunque no se debe olvidar la alta destrucción de puestos de trabajo en este sector económico. La actual crisis en la construcción alcanza de lleno a las nuevas incorporaciones al sector, visualizada en el grupo de los hijos, pues éstos sólo han logrado en el sector el 3\% de sus empleos en el caso de los africanos, y el 7\% de los latinoamericanos.

d) La hostelería-restauración beneficia claramente a los latinoamericanos (17\% de su empleo familiar) frente a los africanos (10\%), en lo que sin duda resulta decisivo el dominio del idioma español, necesario para el trato directo con el cliente, según queda de manifiesto en las encuestas realizadas a empresarios que contratan trabajadores extranjeros (Gozálvez et al., 2006). Por otra parte, la hostelería-restauración es uno de los sectores donde los hijos con empleo de ambos grupos continentales destacan sobre el resto de los respectivos grupos familiares, lo que indica, por el momento, que es un sector de trabajo acorde con sus aspiraciones económicas; en concreto, están empleados en este sector el 23\% de los hijos latinoamericanos y el 14\% de los africanos.

e) El comercio es la primera especialización laboral para todos los grupos familiares de los africanos, con el 28\% del empleo familiar total. Para los latinoamericanos la participación en este sector económico es discreta, pues alcanza el 16\% del empleo familiar. No obstante, el aspecto más decisivo para valorar el empleo en este sector es la distribución de sus em- 
pleos en trabajos por cuenta propia y por cuenta ajena, pues los primeros en alta proporción pueden ser asimilados al comercio ambulante y étnico, mientras el trabajo como asalariados se vincula obviamente a establecimientos comerciales, donde los empresarios exigen dominio del idioma y mayor nivel de instrucción, y, por tanto, es trabajo con mejores posibilidades económicas y sociales. En consecuencia con lo indicado y las características de los inmigrados, en el subsector de comercio por cuenta propia trabaja el 19\% de los familiares africanos reagrupados y el $8 \%$ de los latinoamericanos, mientras en comercio por cuenta ajena el reparto es $9 \%$ y $8 \%$ respectivamente.

Por otra parte, en el significativo grupo laboral de los hijos, los africanos se distribuyen entre un $21 \%$ en comercio propio y un $8 \%$ en comercio por cuenta ajena, es decir, siguen la misma trayectoria que sus padres, mientras entre los hijos de las familias latinoamericanas reagrupadas predomina mucho el trabajo en el comercio por cuenta ajena, el 17\% frente al $6 \%$ en comercio propio. Es decir, entre los hijos africanos, igual que ocurre para el conjunto de todos los familiares con estas nacionalidades, el empleo en el comercio es mayoritariamente un sector «refugio», pues dos tercios de los que trabajan en él lo hacen en la modalidad de comercio propio, asimilable a comercio ambulante y étnico; entre los hijos de los latinoamericanos el significado económico de su trabajo en el comercio es bien distinto, pues dos tercios trabaja en el comercio por cuenta ajena, subsector más acorde con sus aspiraciones sociales y económicas.

f) Los trabajos en el hogar -servicio doméstico y cuidado de enfermos y ancianos- alcanzan importancia muy distinta entre africanos y latinoamericanos, pues en el hogar trabajan el 9\% y el 25\%, respectivamente, de todos los miembros familiares ocupados; estas diferencias sin duda se explican por las mayores afinidades culturales entre los latinoamericanos y los españoles, incluido el idioma común. La segunda característica de estos trabajos es el protagonismo femenino que alcanza al 45\% en las reagrupantes y en las cónyuges latinoamericanas (fig. 6). En tercer lugar, hay que resaltar que los trabajos en el hogar no son valorados como adecuados para satisfacer las aspiraciones sociales de los migrantes. La última característica se deduce del comportamiento del grupo de los hijos en este sector de empleo: trabajan en él el 12\% de los hijos africanos y sólo el 7\% de los hijos latinoamericanos (frente al 24\% del conjunto de los reagrupantes y del 32\% de los cónyuges), sin duda en mejores condiciones que los africanos para aspirar a otro tipo de empleos. 
g) El subsector «otros servicios» es heterogéneo, pero su notable importancia, tanto entre los africanos (16\% de todos sus empleos familiares) como entre los latinoamericanos (20\%), está muy vinculada a los «servicios especializados» (conductores, mecánica, seguridad,...), ejercidos sobre todo por los varones. Interesa destacar la mayor importancia de estos empleos en el grupo familiar de los hijos, con 26\% de su empleo entre los latinoamericanos y 19\% entre los africanos. Estas altas proporciones subrayan la adecuación económica y social de estos empleos con los objetivos de esta inmigración.

\section{REPERCUSIONES SOCIOECÓNOMICAS DE LA CRISIS ACTUAL EN LAS FAMILIAS REAGRUPADAS}

\subsection{El paro laboral en las familias reagrupadas, en 2009-10}

Según las declaraciones de los reagrupantes, las tasas de paro en las familias africanas reagrupadas en la España mediterránea son siempre muy superiores $-39 \%$ de parados sobre 589 activos- a las de las familias latinoamericanas (27\% de parados sobre 993 activos), diferencias que se repiten en todos los grupos familiares, así como en cada una de las tres áreas territoriales estudiadas (fig. 7).

Frente a una tasa media nacional (2009-10) del 19,6\% de paro, que ofrece la Encuesta de Población Activa del INE, las tasas de paro de los africanos encuestados tienen su «mínimo» en el grupo de los reagrupantes con el 35\%, mientras los grupos de cónyuges (mayoría de mujeres) y de hijos alcanzan el 42\%, y el 50\% el grupo de progenitores y otros familiares que también conviven con el reagrupante. En las familias latinoamericanas, aunque sus tasas de paro laboral también sobrepasan ampliamente la media nacional, son más reducidas y más uniformes que las de los africanos, pues oscilan entre el 26\% (los hijos) y el 30\% (los cónyuges).

En las tasas de parados obtenidas de los encuestados destacan dos hechos: en primer lugar, las tasas de paro de los latinoamericanos son menores que la de los africanos en todos los grupos familiares, lo que se explica, una vez más, por la mejor situación ante el trabajo de los primeros (idioma español, mayor nivel de instrucción y cultura afín a la de los autóctonos); las opiniones de los empresarios españoles encuestados que emplean a extranjeros, corroboran en mayoría sus preferencias laborales para los extranjeros que dominen el idioma español, especialmente si el trabajo pertenece a los sectores secundario y terciario (Gozálvez et al., 2006), hecho, por otra parte común en cualquier país. En segundo lugar es destacable las menores cifras de paro entre los hijos de las familias latinoamericanas, $26 \%$ frente al $42 \%$ en los hijos de los africanos, lo que puede ser acorde con una mayor integración del colectivo latinoamericano, ahora y sobre todo en el futuro, pues son los inmigrados que aportan mejor capital humano 
para el trabajo, y también son los que muestran mayores deseos de superación laboral, especialmente cuando se les pregunta sobre su disponibilidad para realizar cursos de formación profesional, tal como se ampliará.

Figura 7. Tasas de paro laboral (2009-2010) de los miembros de las familias reagrupadas en la España mediterránea. Ambos sexos.

1. Reagrupantes; 2. Cónyuges; 3. Hijos; 4. Progenitores y otros; 5. Total miembros de la familia.

1a. Reagrupantes en Cataluña; 1b. Reagrupantes en Comunidad Valenciana; 1c. Reagrupantes en Murcia-Almería

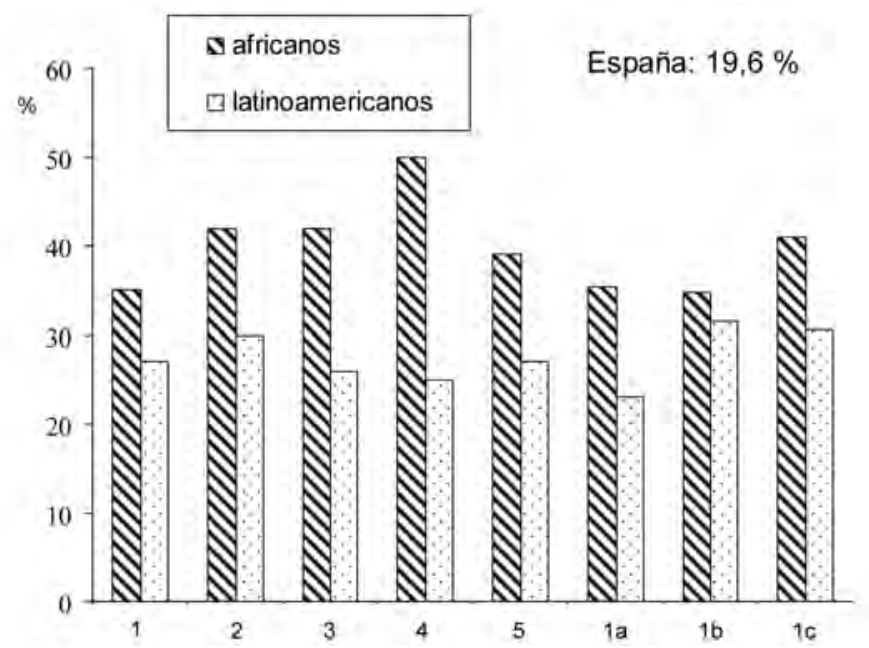

Fuente: ERFEM, 2009-2010. España: EPA, 2009-2010. Elaboración propia

Como es habitual para cualquier indicador entre los estudiados, los reagrupantes que residen en Murcia-Almería alcanzan tasas de paro laboral superiores respecto a los que residen en Cataluña litoral, tanto entre los africanos -41\% y 35\%, respectivamente- como entre los latinoamericanos -31\% en MurciaAlmería, 23\% en Cataluña-. El mayor paro en las provincias del sur sin duda obedece a dos causas principales: por una parte, el capital social más deficiente de los reagrupantes que residen en Murcia-Almería, tanto si son africanos como latinoamericanos, en este caso con predominio de los andinos (Gozálvez et al., 2012b); y, por otra, las mayores y más variadas posibilidades de empleo que ofrece la economía catalana, como es bien sabido.

La duración del paro laboral superior a un año en el momento de realizar la encuesta (2009-10), ofrece tasas que discriminan mucho a los africanos en todos los grupos familiares: así, entre los reagrupantes el paro de larga duración -más 
de un año- incluye al 37\% de estos parados, frente al 19\% entre los latinoamericanos, aunque la discriminación máxima es la que afecta al grupo de los hijos, lo que es una grave preocupación para la integración futura de estos jóvenes africanos. Así, entre los hijos de los africanos la duración del paro superior a un año afecta al $46 \%$ de los que está en paro, frente al 11\% entre los hijos de los latinoamericanos; estas discriminaciones, caso de producirse en situaciones de economía «normalizada», mostrarían posibilidades muy negativas ante su futura integración, precisamente cuando los africanos son los extranjeros que tienen más generalizada y decidida su permanencia definitiva en España (Gozálvez et al., 2012b). Para el total de los miembros de las familias reagrupadas que están en paro laboral (227 parados africanos, 273 latinoamericanos), la proporción de los que padecen paro de larga duración son el 37\% de los parados africanos, frente al 18\% de los latinoamericanos. Esta situación tan desfavorable para las familias africanas, se agrava por ser también el colectivo extranjero que padece mayores carencias de subsidio de desempleo. En efecto, según los reagrupantes encuestados en 2009-10, no reciben subsidios de desempleo el 52\% de los reagrupantes africanos en paro, frente al 34\% de los latinoamericanos, e iguales desigualdades se producen entre los cónyuges, con proporciones negativas que afectan al $69 \%$ y $53 \%$, respectivamente.

\subsection{Número de ocupados por familia reagrupada, en 2009-10}

Las familias reagrupadas en la España mediterránea según su número de ocupados en 2009-10 -348 familias africanas encuestadas, 457 latinoamericanas-, es un indicador ilustrativo de las posibilidades y diferencias económicas y sociales entre africanos y latinoamericanos, siempre con la peor situación para los primeros.

Las familias con cero ocupados es la situación que padece el 28\% de las africanas frente al $11 \%$ de las latinoamericanas (cuadro 2). Esta franja de familias sin ningún ingreso por trabajo es obviamente la más preocupante, ya que la situación negativa real va más allá de las diferencias indicadas si tenemos en cuenta que las familias africanas, según declaran los encuestados, tienen una media de 4,21 miembros por 3,73 de las latinoamericanas (Gozálvez et al. 2012b), a lo que se añade, en relación al empleo, la opuesta situación en el dominio del idioma español y el muy deficiente nivel del instrucción de los africanos, pues el 22\% de estos últimos reagrupantes se encuentran «Sin estudios. Sin título», frente a sólo el 4\% de los latinoamericanos; esta grave situación personal para superar las dificultades para el empleo se multiplica en Murcia-Almería, donde los «Sin estudios. Sin título» son el 44\% de los reagrupantes africanos (Gozálvez et al., 2012b).

En su distribución territorial, las familias africanas que se autodeclaran con cero ocupados llegan al 30\% de su total en Murcia-Almería (cuadro 2), mientras en 
Cataluña litoral disminuyen pero sólo al 26\%; esta escasa diferencia entre el norte y el sur de la España mediterránea hace pensar que esta grave situación económicosocial de las familias africanas está más vinculada a su deficiente capital personal para el empleo (lengua, instrucción), que a las distintas economías de los territorios donde residen. En las familias latinoamericanas las diferencias entre el norte y el sur son más acusadas, ya que las que cuentan con cero ocupados son el $7 \%$ de las familias que residen en Cataluña y el 20\% de las de Murcia-Almería: aquí sin duda suman por igual para agrandar las diferencias tanto las distintas economías territoriales como los menores niveles de instrucción que tienen los latinoamericanos andinos, que son los que predominan en Murcia-Almería (Gozálvez et al., 2012b).

Cuadro 2. Familias africanas y latinoamericanas reagrupadas en la España mediterránea, según su número de ocupados en 2009-10.

\begin{tabular}{|c|c|c|c|c|c|c|c|c|}
\hline \multirow{2}{*}{$\begin{array}{c}\text { Número } \\
\text { ocupados/ }\end{array}$} & \multicolumn{2}{|c|}{$\begin{array}{c}\text { Familias } \\
\text { africanas }\end{array}$} & \multicolumn{6}{|c|}{ Familias africanas residentes en } \\
\cline { 2 - 9 } familia & número & $\%$ & número & $\%$ & número & $\%$ & número & $\%$ \\
\hline 0 & 97 & 27,9 & 32 & 25,8 & 35 & 28,2 & 30 & 30,0 \\
\hline 1 & 163 & 46,7 & 64 & 51,6 & 54 & 43,5 & 45 & 45,0 \\
\hline 2 & 67 & 19,3 & 21 & 17,0 & 26 & 21,0 & 20 & 20,0 \\
\hline 3 & 17 & 4,9 & 3 & 2,4 & 9 & 7,3 & 5 & 5,0 \\
\hline 4 & 3 & 0,9 & 3 & 2,4 & 0 & 0,0 & 0 & 0,0 \\
\hline 5 & 1 & 0,3 & 1 & 0,8 & 0 & 0,0 & 0 & 0,0 \\
\hline Total & 348 & 100,0 & 124 & 100,0 & 124 & 100,0 & 100 & 100,0 \\
\hline
\end{tabular}

\begin{tabular}{|c|c|c|c|c|c|c|c|c|}
\hline \multirow{3}{*}{$\begin{array}{c}\text { Número } \\
\text { ocupados/ } \\
\text { familia }\end{array}$} & \multirow{2}{*}{\multicolumn{2}{|c|}{$\begin{array}{c}\text { Familias } \\
\text { latinoamericanas }\end{array}$}} & \multicolumn{6}{|c|}{ Familias latinoamericanas residentes en } \\
\hline & & & \multicolumn{2}{|c|}{ Cataluña } & \multicolumn{2}{|c|}{ C. Valenciana } & \multicolumn{2}{|c|}{ Murcia-Almería } \\
\hline & número & $\%$ & número & $\%$ & número & $\%$ & número & $\%$ \\
\hline 0 & 50 & 10,9 & 15 & 6,9 & 14 & 10,4 & 21 & 20,2 \\
\hline 1 & 190 & 41,6 & 84 & 38,5 & 66 & 48,9 & 40 & 38,5 \\
\hline 2 & 149 & 32,6 & 84 & 38,5 & 36 & 26,7 & 29 & 27,9 \\
\hline 3 & 44 & 9,6 & 22 & 10,1 & 8 & 5,9 & 14 & 13,5 \\
\hline 4 & 19 & 4,2 & 10 & 4,6 & 9 & 6,7 & 0 & 0,0 \\
\hline 5 & 3 & 0,7 & 2 & 0,9 & 1 & 0,7 & 0 & 0,0 \\
\hline 6 & 1 & 0,2 & 1 & 0,5 & 0 & 0,0 & 0 & 0,0 \\
\hline 7 & 1 & 0,2 & 0 & 0,0 & 1 & 0,7 & 0 & 0,0 \\
\hline Total & 457 & 100,0 & 218 & 100,0 & 135 & 100,0 & 104 & 100,0 \\
\hline
\end{tabular}

Fuente: ERFEM, 2009-10. Elaboración propia 
La mayor parte de las familias encuestadas tienen 1 ó 2 de sus miembros ocupados, que suelen corresponder con el reagrupante y su cónyuge, pues por su juventud los hijos que trabajan en 2009-10 aún representan cifras bajas, aunque éstas también obedecen a la crisis de empleo actual. En concreto, tienen 1 ó 2 ocupados dos tercios de las familias africanas (cuadro 2), aunque de este porcentaje sólo un 19\% es el que incluye al segundo ocupado, evidenciándose la influencia de las bajas tasas de ocupación en las mujeres cónyuges, que son mayoría muy destacada dentro de este grupo familiar (Gozálvez et al., 2012b). Las familias latinoamericanas con 1 ó 2 ocupados son el 74\% del total y de esta proporción un tercio es el que incluye a dos ocupados. Esta diferente importancia del segundo ocupado entre familias africanas -19\%- y latinoamericanas -33\%-, en el que sin duda influyen tanto aspectos culturales sobre la actividad en las mujeres casadas, como la distinta estructura de la inmigración, tiene consecuencias negativas evidentes en el montante de los ingresos económicos familiares, como veremos.

Finalmente, el grupo que teóricamente podríamos calificar como «familias sin problemas de ingresos», son las que en 2009-10 tienen tres o más ocupados, con importancia también muy diferenciada a favor de los latinoamericanos, que acumulan en este tramo el 15\% de sus familias, frente al 6\% de las africanas, proporciones que se repiten o son próximas en cada una de las tres áreas territoriales estudiadas.

\subsection{Los ingresos económicos de las familias reagrupadas (2009-10)}

Los condicionantes de los ingresos económicos que perciben actualmente las familias africanas y latinoamericanas reagrupadas en la España mediterránea son muy variados, pero sin duda destacan las tasas de paro laboral y su duración, el número de ocupados por familia, los sectores de empleo de los inmigrados, su nivel de instrucción o su dominio del idioma español, entre otros. En cualquier caso, tal como se ha mostrado en los apartados anteriores, los indicadores enumerados siempre darán ingresos menores para los africanos que para los latinoamericanos; además, dentro de cada uno de estos dos colectivos, los ingresos son más deficientes para los que residen en Murcia-Almería que para los que viven en Cataluña litoral; esto último, a su vez también depende de las distintas oportunidades laborales que ofrecen las economías de cada uno de los territorios estudiados. Estas diferentes posibilidades de las personas y de las economías territoriales quedan perfectamente reflejadas en las declaraciones de los reagrupantes sobre los ingresos económicos que perciben sus familias (cuadro 3). 
Cuadro 3. Ingresos económicos mensuales de las familias reagrupadas en la España mediterránea. Año 2009-10. Euros mensuales.

\begin{tabular}{|c|c|c|c|c|c|c|c|}
\hline & $\begin{array}{c}\text { Número } \\
\text { familias }\end{array}$ & $\begin{array}{c}\text { Menos } \\
\text { de 300 } \\
\%\end{array}$ & $\begin{array}{c}\text { De 300 } \\
\text { a } 600 \\
\%\end{array}$ & $\begin{array}{c}\text { De 601 } \\
\text { a 1.000 } \\
\%\end{array}$ & $\begin{array}{c}\text { De 1.001 } \\
\text { a 1.500 } \\
\%\end{array}$ & $\begin{array}{c}\text { De 1.501 } \\
\text { a 2.000 } \\
\%\end{array}$ & $\begin{array}{c}\text { Más de } \\
2.000 \\
\%\end{array}$ \\
\hline Africanos, totales & 343 & 7 & 14 & 27 & 29 & 15 & 8 \\
\hline en Cataluña & 122 & 4 & 15 & 22 & 30 & 20 & 9 \\
\hline en C. Valenciana & 120 & 3 & 15 & 24 & 33 & 13 & 12 \\
\hline en Murcia-Almería & 101 & 15 & 12 & 35 & 25 & 10 & 4 \\
\hline Latinoamericanos, totales & 448 & 3 & 4 & 18 & 30 & 24 & 21 \\
\hline en Cataluña & 215 & 2 & 3 & 15 & 27 & 27 & 26 \\
\hline en C. Valenciana & 128 & 4 & 3 & 20 & 34 & 20 & 19 \\
\hline en Murcia-Almería & 105 & 6 & 9 & 21 & 29 & 21 & 15 \\
\hline
\end{tabular}

Fuente: ERFEM, 2009-2010. Elaboración propia

En efecto, si resaltamos, por una parte, los ingresos familiares insuficientes (hasta $1.000 €$ mensuales) y, por otra, los ingresos más altos (más de $2.000 €$ ), las dualidades indicadas (tanto por nacionalidades como por áreas de residencia) quedan totalmente corroboradas, especialmente en las tasas de pobreza, es decir, ingresos medios menores de $1.000 €$ mensuales para familias medias de 4,21 personas en los africanos y de 3,73 en los latinoamericanos.

Además, la insuficiencia familiar de los ingresos menores de $1.000 €$ queda asimismo patente porque, según declaran los reagrupantes, el gasto principal de las familias es la vivienda -así lo declara el 75\% de los encuestados africanos, y el $81 \%$ de los latinoamericanos-, que cuesta entre 300 y $500 €$ mensuales para el $48 \%$ de los africanos y para el $41 \%$ de los latinoamericanos, mientras que para el gasto en vivienda comprendido entre 501 y $700 €$ mensuales, se suma otro $28 \%$ de africanos y latinoamericanos.

Los que ingresan menos de 1.000 € (cuadro 3) -siempre según las declaraciones de los reagrupantes- son el $48 \%$ de las familias africanas -de ellos casi la mitad menos de $600 €$ - frente al 25\% de las familias latinoamericanas. A su vez, en las familias africanas que residen en Cataluña litoral, los ingresos de pobreza afectan al $41 \%$ de ellas, pero para las que viven en Murcia-Almería estos ingresos insuficientes afectan al 62\% de las familias. Entre las familias latinoamericanas se corroboran las mismas tendencias territoriales, aunque afectan a proporciones de familias menores: es decir, los ingresos mensuales menores de $1.000 €$ incluyen al 20\% de las familias que viven en Cataluña y al 36\% de las que residen en Murcia-Almería. En la Comunidad Valenciana los ingresos familiares más bajos ofrecen proporciones intermedias entre las indicadas, pero mucho más próximas a las registradas en Cataluña. 
Las mismas gradaciones, pero inversas, se registran para las familias que ingresan más de $1.500 €$ mensuales, cantidad sin duda más vinculada al número de ocupados por familia -especialmente cuando sobrepasan los $2.000 €$ mensuales-, que a mejoras laborales individuales. En concreto, ingresan más de 2.000 $€$, el 8\% de las familias africanas, pero esta proporción cae a la mitad en MurciaAlmería; entre las familias latinoamericanas, estas mismas proporciones afectan al $21 \%$ y $15 \%$, respectivamente (cuadro 3 ).

\section{ELEMENTOS DE ESTABILIDAD LABORAL EN LAS FAMILIAS REAGRUPADAS}

\subsection{La antigüedad en el empleo actual (2009-2010)}

La antigüedad en el empleo actual de los miembros de las familias reagrupadas, podría ser un indicador de estabilidad de los inmigrados en España, a no ser que la antigüedad sea semiforzada, situación que parece darse sobre todo en la agricultura, tal como se deduce tanto de la proporción decreciente de ocupados en este sector al aumentar la antigüedad del reagrupante en España, como de las manifestaciones explícitas de los inmigrados sobre el carácter semiforzado de este trabajo, repetidas desde antiguo (Gozálvez, dir., 1995).

La antigüedad superior a tres años en el trabajo actual que declaran los reagrupantes encuestados afecta al 54\% de los africanos y al $46 \%$ de los latinoamericanos, diferencias relacionadas fundamentalmente con la mayor antigüedad en España de los primeros, pues los que ya residían en España en 1999 eran el 43\% de los reagrupantes africanos, por sólo el 10\% de los latinoamericanos (Gozálvez et al., 2012b). Las proporciones indicadas sobre antigüedad superior a tres años, se repiten en Cataluña litoral y en C. Valenciana, pero disminuyen entorno a diez puntos en Murcia-Almería, en lo que sin duda intervienen dos causas principales: la inmigración laboral más reciente en estas dos provincias en relación a Cataluña, y la mayor proporción en Murcia-Almería del trabajo agrícola, generalmente no deseado (menores ingresos por su inestabilidad debida a rotaciones en explotaciones minifundistas, dureza del trabajo, falta de salubridad en invernaderos bajo abrigo plástico,...).

Los cónyuges de los reagrupantes, y sobre todo los hijos, rebajan su antigüedad en el empleo actual, dada su incorporación laboral más reciente. Sólo un tercio de los cónyuges de ambos grupos continentales mantienen su trabajo actual con antigüedad superior a tres años; la igualdad de proporciones de los cónyuges africanos y latinoamericanos sin duda denuncia la mayor celeridad con que los latinoamericanos han podido obtener las condiciones para realizar la reagrupación familiar, lo que es acorde a su mejor preparación para el acceso al empleo. 
Dada la juventud de las familias reagrupadas (Gozálvez et al., 2012b), la mayor parte de los hijos se han incorporado al trabajo actual en fechas muy recientes, por lo que tienen antigüedad inferior a un año el $45 \%$ de los hijos africanos y el $60 \%$ de los latinoamericanos, mientras que sobrepasan la antigüedad superior a tres años sólo el 18\% de los respectivos colectivos continentales.

\subsection{Asistencia a cursos de formación profesional}

La asistencia a cursos de formación profesional es un medio necesario para aumentar las capacidades laborales y por consiguiente la estabilidad laboral y la integración de estos inmigrados. De acuerdo con su nivel de instrucción y el dominio del idioma español de estos trabajadores extranjeros (Gozálvez et al., 2012b), los cursos de formación profesional son especialmente necesarios en el caso de los africanos, incluidos los que trabajan en sectores aparentemente con menores exigencias de formación, como es el caso de la agricultura (Gozálvez et al., 2006). Tanto por el frecuente origen urbano de estos inmigrantes (Gozálvez, dir., 1995) como por las exigencias comerciales en el caso de la recolección de frutas y hortalizas, la formación específica para estos trabajadores agrarios sin duda debe incluir cursos de formación profesional.

Pese a los evidentes y necesarios beneficios que proporcionan al trabajador inmigrado los cursos de formación profesional, su rechazo a realizarlos, según las manifestaciones de los reagrupantes encuestados, es excesivamente alto, sobre todo entre quienes más los necesitan por tener mayores carencias formativas. Así, entre el colectivo de africanos manifiestan que no desean asistir a cursos de formación profesional el $62 \%$ de los reagrupantes, el $70 \%$ de los cónyuges y el 53\% de los hijos; en el caso de los latinoamericanos, que poseen mejor capital personal para el acceso a los empleos, el rechazo a asistir a los cursos de formación profesional disminuye considerablemente: dicen no necesitarlos el 46\% de los reagrupantes y de los cónyuges y el $42 \%$ de los hijos. Destaca el menor rechazo a estos cursos por parte de los hijos de ambos grupos de nacionalidades, pese a que se les presupone mejor preparación que a sus padres para acceder al trabajo, actitud que sin duda es alentadora para la futura integración económica y social de este grupo familiar.

Entre los que sí desean asistir a cursos de formación profesional (los encuestados han podido seleccionar un tipo de curso, varios o ninguno), de entre los enumerados en la encuesta, los cursos más solicitados por los reagrupantes africanos varones son los de mecánica (32\%), administrativos (20\%) y agricultura (11\%); las mujeres reagrupantes, de acuerdo con sus «especializaciones» laborales, desean fundamentalmente cursos de cocina (56\%) y administrativos (19\%). Entre los cónyuges (ambos sexos) destacan las preferencias por cursos de 
administrativos (26\%), mientras los hijos (ambos sexos) se inclinan por la mecánica (15\%), cocina (10\%) y administrativos (9\%), pero éstos concentran sus mayores preferencias $(60 \%)$ en el grupo indeterminado de " otros cursos ». Los miembros de las familias latinoamericanas también muestran preferencias destacadas por los cursos administrativos, cocina entre las mujeres, mecánicos entre los varones, y sanidad, que alcanza especial predilección entre las mujeres (29\% entre las reagrupantes). En resumen, las preferencias por los tipos de cursos coinciden para africanos y latinoamericanos en administrativos (todos los grupos familiares), cocina (especialmente entre las mujeres africanas) y mecánicos entre los varones. Los cursos sobre sanidad, más dependientes de un nivel de instrucción adecuado, sólo los solicitan los latinoamericanos, sobre todo mujeres.

En las áreas territoriales estudiadas, las proporciones de los que sí desean asistir a cursos de formación profesional, así como las preferencias por tipos de cursos, mantienen proporciones similares en las tres áreas. No obstante, destaca la solicitud de cursos sobre agricultura entre los reagrupantes africanos de Cataluña litoral (16\%), mientras en Murcia-Almería, donde el trabajo agrario alcanza importancia muy destacada, los cursos sobre agricultura no interesan a ningún grupo familiar, lo que se puede interpretar como rechazo muy generalizado de los inmigrantes a permanecer en esta actividad. La alta proporción indicada para los reagrupantes que residen en Cataluña, sin duda responde a las conocidas preferencias de los empresarios agrarios de esta área en la selección de los trabajadores para sus explotaciones, sobre los que poseen estos cursos, pues en este caso los trabajadores acrecientan mucho su eficacia laboral; en cualquier caso, el grupo de hijos, tanto africanos como latinoamericanos, están totalmente ajenos a los cursos sobre agricultura en toda la España mediterránea estudiada.

\subsection{Los trabajos actuales en relación a las expectativas del trabajador}

Los trabajos actuales en relación a las expectativas de los miembros de las familias reagrupadas merecen mayoritariamente respuestas positivas, sobre todo entre los reagrupantes ( $74 \%$ entre los africanos, $71 \%$ entre los latinoamericanos), aunque la satisfacción mayor es para los que residen en Cataluña litoral (82\% para los africanos, $74 \%$ para los latinoamericanos), y la menor para los de Murcia-Almería (56\% para los africanos, $67 \%$ para los latinoamericanos). No obstante, para los cónyuges y para los hijos (en la apreciación de los reagrupantes, que son los que contestan a la encuesta familiar) sus trabajos actuales ofrecen satisfacción menor respecto a sus expectativas, pues rebajan la respuesta positiva a un $60 \%$ los africanos y a un $64 \%$ los latinoamericanos.

La mayor satisfacción que muestran los reagrupantes respecto a sus cónyuges e hijos sin duda tiene causas variadas, entre las que se podrían citar el largo 
y difícil proceso de mejora laboral que los reagrupantes han vivido en España, mientras para los cónyuges e hijos tal proceso de mejora laboral es mucho más reducido o simplemente todavía no ha podido realizarse por su presencia más reciente en España, como resultado de su reagrupación. Entre esas mejoras laborales de los reagrupantes, sin duda hay que destacar su regularización laboral, que, como vimos, en la actualidad afecta positivamente a proporciones muy altas de los reagrupantes (94\% en los africanos, 92\% en los latinoamericanos), mientras trabajan sin regularización laboral el 22-18\% de los cónyuges y el 13-15\% de los hijos, respectivamente.

Entre los miembros familiares que dan respuesta negativa a la relación trabajo actual-expectativas del inmigrado, sus proporciones se reparten con bastante equilibrio y lógica en tres motivos principales, además del indeterminado «otros»: a) Inadecuación del trabajo a la cualificación profesional que poseen, lo que alcanza mayor importancia -entorno al 25\%-entre los latinoamericanos, más instruidos, que entre los africanos -20\%-. b) Salario insuficiente, queja mucho más frecuente entre los africanos, con proporciones que oscilan entre 31\% para los reagrupantes que residen en Murcia-Almería y un 47\% para los reagrupantes de Cataluña (área mucho más cara para vivir); entre los latinoamericanos, la queja de salario insuficiente es menor, pues sólo la manifiesta el 22\% de los reagrupantes que residen en Cataluña. Estas diferencias sobre salarios insuficientes entre africanos y latinoamericanos son acordes a los distintos montantes de los respectivos ingresos familiares que declaran los reagrupantes encuestados, tal como se expuso. c) La inestabilidad del trabajo actual es la tercera causa importante para mostrar la insatisfacción del trabajo actual respecto a las expectativas del trabajador familiar. Como ocurre con todos los indicadores, los africanos, según sus declaraciones, son mucho más castigados que los latinoamericanos en la carencia de estabilidad laboral: aducen esta causa como respuesta negativa a la relación trabajo-expectativas del trabajador el 28\% de los miembros de las familias africanas, frente al 16\% de las latinoamericanas.

\subsection{Horas de trabajo por semana}

Las horas de trabajo por semana que realizan en 2009-10 los miembros de las familias reagrupadas, se pueden agrupar en tres categorías: a) los que trabajan menos de 35 horas, cuyas proporciones coinciden con los que declaran trabajar a tiempo parcial; b) los que realizan jornadas de trabajo habituales, entre 35 y 40 horas, y c) los que tienen sobrecarga laboral, con más de 40 horas semanales.

Los que trabajan menos de 35 horas semanales alcanzan su menor tasa entre los reagrupantes africanos encuestados (7\% del total), aunque éstos tienen desigual reparto entre Cataluña litoral-C. Valenciana (con el 3-4\%) y en Murcia- 
Almería, donde alcanzan el 15\%, sin duda a causa de su frecuente ocupación en explotaciones agrícolas minifundistas, que, por definición, han de contratar para un número limitado de jornadas laborales (siembra, recolección). Los reagrupantes latinoamericanos, con parte importante de mujeres, aumentan su tasa en las jornadas laborales a tiempo parcial en un 16\% de su total, proporción que se repite en las tres áreas territoriales estudiadas. En los grupos de cónyuges y de hijos aumentan mucho los que trabajan a tiempo parcial (menos de 35 horas semanales), sobre todo entre los africanos, pues un tercio de ellos lo hace con estos horarios, mientras la cuarta parte de los cónyuges e hijos latinoamericanos también trabaja con esta dedicación parcial.

Los miembros familiares que trabajan con sobrecarga horaria, más de 40 horas semanales, afecta a más de la mitad (51\%) de los reagrupantes africanos, mientras entre los latinoamericanos esta tasa desciende ocho puntos; además, un $20 \%$ de los reagrupantes de ambos colectivos declara que trabaja más de 50 horas semanales. Los bajos salarios y la ocupación mayoritaria en sectores como el hogar, el comercio propio y la hostelería-restauración, pueden explicar estas sobrecargas horarias de las jornadas de trabajo. En los grupos de cónyuges e hijos la sobrecarga laboral -más de 40 horas semanales- es mucho menos frecuente, pues afecta entre la cuarta parte y un tercio de sus totales.

Las jornadas laborales habituales -35 a 40 horas semanales- afectan al $40 \%$ de los reagrupantes de ambos colectivos de nacionalidades, e incluso a proporciones mayores de los cónyuges e hijos latinoamericanos (49\%). Por el contrario, los cónyuges e hijos africanos sólo un tercio tienen jornadas laborales habituales, mientras los otros dos tercios se reparten por igual entre los que trabajan a tiempo parcial y los que trabajan con sobrecarga de horarios; es decir, como ocurre con otros indicadores, cónyuges e hijos africanos son los que tienen horarios laborales más precarios.

\subsection{Problemas laborales y de salario}

Los problemas laborales y de salarios de los miembros de las familias reagrupadas son denunciados en la encuesta mediante respuestas múltiples (por lo que se contabilizan 819 respuestas entre los africanos y 1.411 entre los latinoamericanos). Los problemas más mencionados por los reagrupantes tanto africanos como latinoamericanos se reparten por igual (entorno al 15\% de las respuestas) entre horarios de trabajo excesivos, sueldos insuficientes y carencias de contrato. Sin embargo, en el grupo de hijos, también de ambos colectivos continentales, el primer problema, horario de trabajo excesivo, se aminora considerablemente, pues para éstos las jornadas laborables normalizadas y las de tiempo parcial afectan a dos tercios de su total. 
Los miembros familiares que manifiestan que no han tenido problemas laborales ni salariales durante su experiencia laboral en España son la cuarta parte de los reagrupantes de ambos continentes, más de un tercio de los cónyuges y un $45 \%$ de los grupos de hijos. Así pues, los problemas laborales aumentan, lógicamente, cuando se prolonga la experiencia laboral en España, es decir, son máximos entre los reagrupantes y mínimos entre sus hijos; la situación más favorable de estos últimos sin duda también puede responder a su mayor integración en la sociedad de inserción.

\section{CONCLUSIONES}

El futuro de los flujos de inmigración extrajera en España ha iniciado un nuevo ciclo impuesto bruscamente por la crisis económico-laboral vigente desde 2008. El rápido y desastroso incremento de las tasas de paro laboral ha forzado a la autorregulación de la inmigración, tanto en los países de origen como en España mediante los retornos de inmigrantes -incentivados y/o voluntarios-, situación que afecta sobre todo a los latinoamericanos, que son precisamente los inmigrados más numerosos entre los establecidos en España por motivos de mejora laboral, y también los que cuentan con mejores perspectivas de futuro en sus países de origen.

El retorno a un nuevo ciclo inmigratorio con las características laborales y de número de los años 1998-2007 parece desvanecido. Sin embargo, sí es posible contar durante los próximos años con una nueva inmigración, ahora por motivos de reagrupación familiar, demandada por los inmigrados ya establecidos en España, a resultas de su juventud, de su cultura diferente a la de los autóctonos y de su firme voluntad de permanencia en España para una buena parte de ellos. La insuficiente fecundidad establecida en España, el envejecimiento del país, ya con tasas muy altas y en crecimiento progresivo, así como el cambio en las estructuras laborales de los españoles, también pueden incentivar estos nuevos ciclos inmigratorios, pero ahora con flujos más controlados.

Africanos y latinoamericanos ya son en España los grandes protagonistas de la inmigración por motivos de reagrupación familiar (Gozálvez et al., 2012b), y sin duda continuarán siéndolo en el futuro. En efecto, según la encuesta en la que se basa esta investigación, los inmigrados de ambos grupos continentales manifiestan, en altas proporciones, voluntad de permanencia en España de larga o definitiva duración, especialmente para sus hijos, al mismo tiempo que también desean apoyar nuevas inmigraciones de familiares.

En este sentido destaca la mayor firmeza y generalización de deseos de permanencia en España declarada por los reagrupantes africanos, a pesar de que este colectivo es el que padece en España las situaciones más desfavorables para su integración económica y social; la explicación parcial a esta actitud sin duda 
se apoya en las negativas perspectivas de desarrollo y bienestar que por el momento padecen sus países de origen, y que a su vez actúan como barreras ante cualquier retorno a esos países. En efecto, buena parte de los inmigrantes africanos cuentan con características personales muy deficientes para su acceso y promoción laboral en España, sobre todo por sus elevadas tasas en los niveles de instrucción insuficiente y, obviamente, por sus carencias en el manejo del idioma español (Gozálvez et al., 2012b). Este escaso capital humano para el trabajo, se ve agravado por su aparente menor interés -en comparación a los latinoamericanos- en asistir a cursos de formación profesional; desinterés que afecta tanto a los africanos reagrupantes como a sus cónyuges e hijos.

El grupo de los hijos de las familias africanas y latinoamericanas reagrupadas en la España mediterránea siempre muestra mejores capacidades y aptitudes que sus padres -reagrupantes y cónyuges- para su promoción laboral, y por tanto para su mejor integración actual y futura en la sociedad española.

La encuesta realizada en paralelo a reagrupantes africanos y latinoamericanos, permite comparar los indicadores sociolaborales, con resultado siempre menos favorable para los africanos, sin duda como consecuencia de su capital humano inicial más deficiente. Aunque la regulación laboral de los reagrupantes en su primer trabajo en España ofrece idéntica situación de altísima irregularidad -trabajo sin contrato laboral- para africanos y latinoamericanos, los africanos, tal como se ha expuesto, perpetúan con el paso del tiempo mayores precariedades laborales en todos los indicadores económico-laborales recogidos en la encuesta específica realizada por este equipo investigador.

Por otra parte, las distintas variables socio-laborales estudiadas, siempre muestran situaciones más negativas en Murcia-Almería que en Cataluña litoral, lo que se vincula con las posibilidades de una estructura económica más reducida e inestable en estas provincias del sur; a su vez, estas conocidas características económicas de Murcia-Almería, se ven «reforzadas» por un capital humano más deficiente de los reagrupantes y sus familias asentados aquí, tanto africanas como latinoamericanas.

En conclusión, según los datos aportados por la encuesta realizada en 20092010 sobre las características sociodemográficas y económico-laborales de los miembros (reagrupantes, cónyuges, hijos, otros miembros de la familia) de las familias africanas y latinoamericanas reagrupadas en la España mediterránea, las políticas y acciones a desarrollar por las administraciones de España para conocer a estos inmigrantes y su futuro, y para posibilitar su integración del modo más completo y eficiente, deben tener en cuenta las distintas peculiaridades de los inmigrantes según sus países de origen, y según las posibilidades y características estructurales de sus territorios de residencia en España. 
La consolidación actual y futura en España de elevados contingentes de inmigrantes que hayan alcanzado o alcancen reagrupación familiar -que en el caso africano ya tienen pirámides demográficas con gran vitalidad infantil-, sin duda requieren emprender nuevas políticas de integración orientadas específicamente a las familias reagrupadas. Ėstas, por definición y costes económicos y sociales, tienen obviamente voluntad de permanencia en España de larga o definitiva duración. La incorporación a la sociedad española de estas jóvenes familias con plenas obligaciones y derechos, obviamente debe beneficiar tanto a los nuevos ciudadanos como a los autóctonos. Las deficiencias demográficas de España en fecundidad y en envejecimiento, sin dudad también deben ser valoradas en el diseño de las políticas de inmigración familiares, y en este sentido deben conjugarse con otros problemas y dificultades que tiene el país a corto plazo, sobre todo en relación con el mercado laboral y su cambio de estructura para los trabajadores españoles.

\section{BIBLIOGRAFÍA}

Bel Hadj Zekri, A. (1996): «L'émigration des Tunisiens vers l'Europe occidentale: tendances récentes et perspectives», in Conférence méditerranéenne sur la population, les migrations et le développement. Actes, deuxième partie: tables rondes et Forum, Strasbourg, Conseil d'Europe, Direction des Affaires Sociales et Economiques.

Cohen, A.; Berriane, M. (Dir.) (2011): De Marruecos a Andalucía: migración y espacio social, Edit. Universidad de Granada, 428 p.

Cusi Echaniz, P. (2011): «Immigration et crise économique en Espagne», Futuribles, $\mathrm{n}^{\circ} 378$, p. 23-40.

Dumont, J.-F. (2008) : «Immigration étrangère et développement local en France», Futuribles, n 343, p. 5-20.

Fadloullah, A. (1996) : «Croissance démographique et migrations au Maroc», in Di Comite, L. ; Cardamone, A. F. : Crescita démographica e migrazioni internationali nel bacino mediterraneo, Quaderni 11, Università degli Studi di Bari, Dipartimento per lo studio delle società mediterranee, Cacucci Editore, p. 41-56.

GonZÁlez PÉrez, J. M. (2010): «La primera generación de inmigrantes extranjeros en Galicia. Condiciones de vida y relación con el destino según los colectivos estudiados», Migraciones, n² 28, p. 87-125.

GozÁlvez PÉREz, V. (1990): «El reciente incremento de la población extranjera en España y su incidencia laboral», Investigaciones Geográficas, n 8, p. 7-36.

GozÁlvez Pérez, V. (Dir.) (1995): Inmigrantes marroquíes y senegaleses en la España mediterránea, Valencia, Generalitat Valenciana, Conselleria de Treball i Afers Socials, 442 p. 
Gozálvez Pérez, V. et al. (2005): «La inmigración extranjera en España: aumento exponencial, diversificación geográfica y posibilidades de integración», in DI Comite, L.; Rodríguez, V.; Girone, S.: Sviluppo demografico e mobilità territoriale delle popolazioni nell'area del Mediterraneo: Italia e Spagna, due paesi a confronto, Università degli Studi di Bari, Dipartimento per lo studio delle società mediterranee, p. 147-178.

Gozálvez Pérez, V. et al. (2006): «Las trabajadoras extranjeras en la España mediterránea. La perspectiva empresarial», Estudios Geográficos, LXVII, 261, p. 523-547.

GozÁlvez Pérez, V. (2010): «Los extranjeros residentes en España: su aportación a la demografía», Investigaciones Geográficas, n 52, p. 99-136.

GozÁlvez Pérez, V. (2012a): «El proceso de inmigración extranjera en España, 1985-2010» in A cura di Valleri, M.A.; Pace, R.; Girone, S.: Il Mediterraneo: uno studio e una passione. Scritti in onore di Luigi Di Comite, p. 137-172, Bari, Editore Cacucci.

GozÁlvez Pérez, V. et al. (2012b): «La reagrupación familiar de africanos y latinoamericanos en la España mediterránea. Dinámicas y estructuras sociodemográficas», Estudios Geográficos, vol. LXXIII, 273, p. 507-549.

GozÁlvez Pérez, V. y López Trigal, L. (1999): «Jornaleros extranjeros en el campo español», Ería, n 49 , p. 213-229.

IÇDUYGU, A. (1996): «Les migrations de la Turquie à destination de l'Europe occidentale: tendances récentes et perspectives», in Conférence méditerranéenne sur la population, les migrations et le développement. Actes, deuxième partie: tables rondes et Forum, Strasbourg, Conseil d'Europe, Direction des Affaires Sociales et Economiques.

Pumares Fernández, P. (2006): «Efectos de la inmigración regularizada sobre el cambio en la estructura por regímenes y grupos de cotización de la Seguridad Social», Estudios Geográficos, vol. LXVII, n² 261, p. 607-634.

Pumares, P. y Jolivet, D. (2011): «Marcos socioespaciales de la inserción de los inmigrantes en Andalucía: los componentes principales», en CoHen, A. y BERRIANE, M. (dir.): De Marruecos a Andalucía: migración y espacio social, Granada, Editorial de la Universidad de Granada, p. 205-256.

ReHER, D.-S. (Dir.) (2008): Informe Encuesta Nacional de Inmigrantes (ENI2007), Madrid, Instituto Nacional de Estadística, Ministerio de Trabajo e Inmigración, 153 p. Disponible en web: http://www.ine.es/

Tribalat, M. (2012): "Controverse sur les migrations. À propos des ouvrages Exceptional People et Immigrant Nations», Futuribles, n 386, p. 23-32. 